

\section{DISCLAIMER}

This report was prepared as an account of work sponsored by an agency of the United States Government. Neither the United States Government nor any agency Thereof, nor any of their employees, makes any warranty, express or implied, or assumes any legal liability or responsibility for the accuracy, completeness, or usefulness of any information, apparatus, product, or process disclosed, or represents that its use would not infringe privately owned rights. Reference herein to any specific commercial product, process, or service by trade name, trademark, manufacturer, or otherwise does not necessarily constitute or imply its endorsement, recommendation, or favoring by the United States Government or any agency thereof. The views and opinions of authors expressed herein do not necessarily state or reflect those of the United States Government or any agency thereof. 


\section{DISCLAIMER}

Portions of this document may be illegible in electronic image products. Images are produced from the best available original document. 


\title{
A MODEL TO PREDICT SWELLING, GAS RELEASE, AND DENSIFICATION IN OXIDE FUELS (AWBA Development Program)
}

\author{
C. C. Dollins
}

June 1978

Contract EY-76-C-11-0014

Printed in the United States of America

Available from the

National Technical Information Service

U. S. Department of Commerce 5285 Port Royal Road

Springfield, Virginia 22151

This report was prepared as an account of work ponsored by die United Shares Govemment. Naither the Enired Energy. nor any of their employees, nor any of their Cons any warranty, express or implied, or assumes any legal lability un iespunsibility for the accuracy, eompleteness on usc fulitess of any information, apparatis, produat of process disclosed, or represents that its use would not infringe privately owned rights.

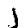

This document is an interim memorandum prepared primarily for internal reference and does not represent a final expression of the opinion of Westinghouse. When this memorandum is distributed externally, it is with the express understanding that Westinghouse makes no representation as to completeness, accuracy, or usability of information contained therein.

\section{BETTIS ATOMIC POWER LABORATORY WEST MIFFLIN, PENNSYLVANIA}

Operated for the U. S. Department of Energy by WESTINGHOUSE ELECTRIC CORPORATION 
This report wae prepared as an account of work sponsored by the United States Government. Neither the United States, nor the United States Department of Energy, nor any of their employees, nor any of their contractors, subcontractors, or their employees, makes any warranty, express or implied, or assumes any legal liability or responsibility for the accuracy, completeness or usefulness of any information, apparatus, product or process disclosed, or represents that its use would not infringe privately owned rights. 
The Shippingport Atomic Power Station located in Shippingport, Pennsylvania was the first large-scale, central-station nuclear power plant in the United States and the first plant of such size in the world operated solely to produce electric power. This project was started in 1953 to confirm the practical application of nuclear power for largescale electric power generation. It has provided much of the technology. being used for design and operation of the commercial, central-station nuclear power plants now in use.

Subsequent to development and successful operation of the Pressurized Water Reactor in the DOE-owned reactor plant at the Shippingport Atomic Power Station, the Atomic Energy Commission in 1965 undertook a research and development program to design and build a Light Water Breeder Reactor core for operation in the Shippingport Station. In 1976, with fabrication of the Light Water Breeder Reactor (LWBR) nearing completion the Energy Research and Development Administration established the Advanced Water Breeder Applications program (AWBA) to develop and disseminate technical information which would assist U.S. industry in evaluating the LWBR-concept. All three of these reactor development projects have been administered by the Division of Naval Reactors with the goal of developing practical improvements in the utilization of nuclear fuel resources for generation of electrical energy using water-cooled nuclear reactors.

The objective of the Light Water Breeder Reactor project has been to develop a technology that would significantly improve the utilization of the nation's nuclear fuel resources employing the well-established water reactor technology. To achieve this objective, work has been directed toward analysis, design, component tests, and fabrication of a water-cooled, thorium oxide fuel cycle breeder reactor to install and operate at the Shippingport Station. Operation of the LWBR core in the Shippingport Station started in the Fall of 1977 and is expected to be completed in about 3 to 4 years. Then the fissionable fuel inventory of the core will be measured. This effort, when completed in about 2 to 3 years after completion of LWBR core operation, is expected to confirm that broeding actually took place.

The Advanced Water Breeder Applications (AWBA) project was initiated to develop and disseminate technical information that will assist U.S. industry in evaluating the LWBR concept for commercial-scale applirations. The project will explore some of the problems that would be laced by industry in adapting technology confirmed in the LWBK program. Information to be developed includes concepts for commercialscale prebreeder cores which will produce uranium-233 for light water breeder cores while producing electric power, improvements for breeder cores based on the technology developed to fabricate and operate the Shippingport LWBR core, and other information and technology to aid in evaluating commercial-scale application of the LWBR concept.

Technical information developed under the Shippingport, LWBR, and AWBA projects has been and will continue to be published in technical memoranda, one of which is this present report. 


\section{INTRODUCTION}

II. MODEL DESCRIPTION

A. Grain Interior Gas Bubble Behavior for Bubble Radius $<25 \AA$

B. Intragranular Bubble Behavior When the Bubble Radius $>25 \AA$

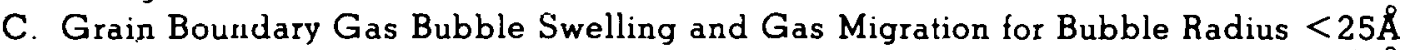

D. Grain Boundary Gas Bubble Swelling and Gas Migration for Bubble Radius $>25 \AA$

E. Grain Edge Gas Bubble Swelling and Gas Migration

F. Tunnel Formation

G. Temperature Gradients

II. Intragranular Densitication

I. Damage Casrades

J. Pore Behavior

K. Densification of Intergranular Porosity

III. CUMPARISON WITH EXPERIMENTAL DATA 20

IV. SUMMARY AND CONCLUSIONS

V. ACKNOWLEDGMENTS ? 21

VI. REFERENCES 21

\section{LIST OF TABLES}

Table Title

$1 \quad$ Swelling and Gas Release Data of Hilberl el al.

2 Comparisons Between Model and Data of Freshley et al.

3 Comparisons Between Model and Data of Banks

\section{LIST OF ILLUSTRATIONS}

1 Comparisons Between Theory and Data of Lewis (Reference 20) for the Release of Gas in $\mathrm{UO}_{2}$

2 Comparisons Between Theory and Data of Zimmermann (Reterence 21) for the Release of $\mathrm{Gas}$ in $\mathrm{UO}_{2}-20 \% \mathrm{PuO}_{2}$ 


\section{LIST OF ILLUSTRATIONS (Cont)}

Comparison Between Theory and Data of Hilbert et al. (Reference 22) That Shows Swelling Versus Average Fuel Temperatures

4 Gas Release Data of Bellamy and Rich (Reference 23) Versus Burnup

5 Comparison Between the Predicted and Observed Densification Data of Freshley et al. (Reference 24)

Comparison Between the Predicted and Observed Swelling Data of Banks (Reference 25) 


\section{NOMENCLATURE}

\section{Symbol}

$\dot{\mathbf{a}}$

A

$\dot{\mathrm{a}}_{\mathrm{b}}$

$\dot{a}_{c}$

$\dot{a}_{e}$

b

$h^{\prime}$

$\mathrm{B}_{\mathrm{b}}$

C

$C^{\prime}$

$<\mathrm{C}>$

$\mathrm{C}_{\mathrm{b}}$

$c_{b}^{\prime}$

$\left\langle\mathrm{C}_{\mathrm{b}}\right\rangle$

$\mathrm{C}_{r}$

$\mathrm{C}_{\mathrm{e}}$

$\mathrm{C}_{\theta}^{\prime}$

$\mathrm{C}_{\mathrm{I}}$

$\mathrm{C}_{\mathrm{l}_{\mathrm{b}}}$

c。

c.

D

$\mathrm{D}_{\mathrm{b}}$

Gas generation rate (atom fraction per second)

$1.19 \times 10^{-22} \exp (-100000 / \mathrm{RT}) \mathrm{cm}^{5} / \mathrm{sec}$ for $\mathrm{UO}_{2} ; 1.19 \times 10^{-22}$

$\exp (-125000 / \mathrm{RT}) \mathrm{cm}^{\mathrm{S}} / \mathrm{sec}$ for $\mathrm{ThO}_{2}$

Rate that gas atoms go to the grain boundaries in atom fraction per second of grain boundary sites

Rate at which gas atoms migrate to corner bubbles

Rate at which gas arrives at the grain edge from the boundary (in atom fraction per second)

Tunnel radius $(\mathrm{cm})$

$3.86 \times 10^{-8} \mathrm{~cm}$, Burgers vectur fur $\mathrm{UO}_{2} ; 3.52 \times 10^{\circ} \mathrm{cm}$ for $\mathrm{IhO}_{2}$ (See $\lambda$ )

$\left(\frac{1.1}{2 \gamma \alpha \sin \varphi}\right)^{1 / 2}$

Gas concentration in grain interior (in atom fraction)

Probability that a bubble lattice site is occupied by a bubble

Average gas concentration in grain interior (in atom fraction)

Grain boundary gas atom concentration (in atom fraction)

Fraction of grain boundary bubble sites occupied by grain boundary bubbles

Average gas concentration on the boundary (in atom fraction)

Concentration of isolated gas atoms beyond which nucleation of permanent bubbles will occur (in atom fraction)

Gas concentration at grain boundary edges (in atom fraction)

Fraction of grain boundary edge bubble sites occupied by grain boundary edge bubbles (in atom fraction)

Concentration of single gas atoms in matrix (in atom fraction)

Concentration of isolated grain boundary gas atoms (in atom fraction)

$\exp (-47000 / \mathrm{RT})$, equilibrium vacancy concentration for $\mathrm{UO}_{2}$; $\exp (-58750 / \mathrm{RT})$ for $\mathrm{ThO}_{2}$ (in atom fraction)

Vacancy concentration (in atom fraction)

Gas diffusion coefficient $\left(\mathrm{cm}^{2} / \mathrm{sec}\right)$

Bubble diffusion coefficient $\left(\mathrm{cm}^{2} / \mathrm{sec}\right)$ 


\section{NOMENCLATURE (Cont)}

\author{
Symbol \\ Definition \\ $\mathrm{D}_{\mathrm{g}}$ \\ $\mathrm{D}_{\mathrm{gb}}$ \\ $\mathrm{D}_{\mathrm{i}} \quad\left(10^{13}\right)\left(3.86 \times 10^{-8}\right)^{2} \exp [-(0.3)(23050) / \mathrm{RT}] / 6$, interstitial diffusion coefficient \\ $\left(\mathrm{cm}^{2} / \mathrm{sec}\right)$ \\ $\mathrm{D}_{\mathrm{s}}$ \\ $\mathrm{D}_{\mathrm{v}}$ \\ $\mathrm{D}_{\mathbf{v}_{\mathbf{q}}}$ \\ $\mathrm{E}_{\ell}$ \\ f \\ $\dot{\mathrm{f}}$ \\ $f_{b}$ \\ k \\ $\mathrm{m}$ \\ $<\mathrm{m}>$ \\ $\mathrm{m}_{\mathrm{b}}$ \\ $\mathrm{m}_{\mathrm{e}}$ \\ n \\ $\bar{n}$ \\ $\mathbf{N}^{\prime}$ \\ $\mathrm{N}^{\prime \prime}$ \\ $<N>$ \\ $\mathbf{n}_{\mathrm{b}}$ \\ $<\mathrm{n}_{\mathrm{b}}>$ \\ $\mathbf{n}_{\mathrm{b}}^{\prime}$ \\ $\overline{\mathbf{n}}_{\mathrm{b}}^{\prime}$ \\ $7.6 \times 10^{-6} \exp (-71500 / \mathrm{RT})+\left(2.5 \times 10^{-7}\right)^{2} / 6 \mathrm{~T}$, gas atom diffusion coefficient for \\ $\mathrm{UO}_{2} ; 7.6 \times 10^{-6} \exp (-89375 / \mathrm{RT})+\left(2.5 \times 10^{-7}\right)^{2} / 6 \tau$ for $\mathrm{ThO}_{2}\left(\mathrm{~cm}^{2} / \mathrm{sec}\right)$ \\ $3 \exp \left(-34 \times 10^{3} / \mathrm{T}\right) \mathrm{cm}^{2} / \mathrm{sec}$, self-diffusion coefficient along the grain boundary for \\ $\mathrm{UO}_{2} ; 3 \exp \left(-43 \times 10^{3} / \mathrm{T}\right)\left(\mathrm{cm}^{2} / \mathrm{sec}\right)$ for $\mathrm{ThO}_{2}$ \\ $560 \times 10^{4} \mathrm{exp}\left(-5.95 \times 10^{4} / \mathrm{T}\right) \mathrm{cm}^{2} / \mathrm{sec}$, surface self-diffusion coefficient for $\mathrm{UO}_{2} ; 560$ \\ $\times 10^{4} \exp \left(-7.44 \times 10^{4} / \mathrm{T}\right) \mathrm{cm}^{2} / \mathrm{sec}$ for $\mathrm{ThO}_{2}$ \\ $3 \times 10^{-2} \exp (-47000 / \mathrm{RT}) \mathrm{cm}^{2} / \mathrm{sec}$, vacancy diffusion coefficient for $\mathrm{UO}_{2} ; 3 \times 10^{-2}$ \\ $\exp (-58750 / \mathrm{RT}) \mathrm{cm}^{2} / \mathrm{sec}$ for $\mathrm{ThO}_{2}$ \\ Vacancy diffusion coefficient along the grain boundaries $\left(\mathrm{cm}^{2} / \mathrm{sec}\right)$ \\ $0.719 R_{g^{\prime}}$ grain edge length $(\mathrm{cm})$ \\ Total fraction of gas released \\ Fission rate (in fissions $/ \mathrm{cm}^{3} \mathrm{sec}$ ) \\ Relative grain boundary bubble jump frequency $\left(\sec ^{-1}\right)$ \\ $1.38 \times 10^{-16}$, Boltzmann's constant $\left(\mathrm{erg} \mathrm{deg}^{-1}\right)$. \\ Number of gas atoms per $\mathrm{cm}^{3}$ \\ Number of gas atoms in the matrix per $\mathrm{cm}^{3}$ \\ Number of gas atoms per $\mathrm{cm}^{2}$ of boundary \\ Number of gas atoms on grain boundary edge per $\mathrm{cm}$ of edge \\ Number of gas atoms in a bubble \\ Number of jumps a bubble makes before cualescence \\ Number of matrix bubbles per $\mathrm{cm}^{3}$ \\ Maximum number of atoms in a matrix bubble just before coalescence \\ Average number of gae atoms in a bubble \\ Number of atoms in a grain boundary hubble \\ Average number of gas atoms in a grain boundary bubble \\ Number of jumps a grain boundary bubble makes \\ Number of jumps a grain boundary bubble makes before coalescence
}




\section{NOMENCLATURE (Cont)}

Symbol

$\mathrm{N}_{\mathrm{b}}$

$<\mathrm{N}_{\mathrm{b}}>$

$\mathrm{N}_{\mathrm{b}}^{\prime}$

$\mathrm{n}_{\mathrm{c}}$

$\mathrm{n}_{\mathrm{c}}^{\prime}$

$\mathrm{N}_{\mathrm{d}}$

$\mathrm{n}_{\mathrm{e}}$

$\left\langle n_{e}\right\rangle$

$\underline{\mathrm{n}_{\mathrm{e}}}$

$\mathrm{n}_{\mathrm{e}}^{\prime}$

$\overline{\mathrm{n}}_{\mathrm{e}}^{\prime}$

$\mathrm{N}_{\mathrm{e}}$

$\left.<\mathrm{N}_{\mathrm{e}}\right\rangle$

$\mathrm{n}_{\mathrm{g}}$

No

$\mathbf{N}_{\mathrm{p}}$

$\mathbf{N}_{\mathrm{p}}^{\prime}$

$\mathrm{P}$

$\mathrm{P}_{\mathrm{g}}$

$P_{g}^{\prime}$

$\mathrm{Q}^{*}$

$\mathbf{r}$

$<\mathrm{r}>$

$\overline{\mathrm{R}}$

$R^{\prime}$

$\mathbf{I}_{b}$

Number of gas atoms in a boundary bubble at destruction

Average number of bubbles on the grain boundary per $\mathrm{cm}^{2}$

Number of bubbles per $\mathrm{cm}^{2}$ of grain boundary

Number of atoms in a matrix bubble of radius $25 \AA$

Number of atoms in a corner bubble

Number of damage cascades per $\mathrm{cm}^{3}$

Number of gas atoms in an edge bubble

Average number of atoms in grain edge bubble

Number of gas atoms in an edge bubble at destruction by fission fragment

Number of grain boundary edge bubble jumps

Number of grain boundary edge bubble jumps to coalescence

Number of gas bubbles per unit length of grain boundary edge (one unit length equals

$1 \mathrm{~cm}$ )

Average number of bubbles on the grain edge per $\mathrm{cm}$

Number of gas atoms in an intragranular pore

$\Omega^{-1}=$ Number of lattice sites per $\mathrm{cm}^{3}$

Number of intragranular fabrication pores per $\mathrm{cm}^{3}$

Number of initial grain boundary fabrication pores per $\mathrm{cm}^{3}$

External pressure (dynes $/ \mathrm{cm}^{2}$ )

Fission gas pressure within the intragranular pores (dynes $/ \mathrm{cm}^{2}$ )

Gas pressure in corner pores (dynes/cm²)

$100000 \mathrm{cal} / \mathrm{mole}$, heat of transport for $\mathrm{UO}_{2} ; 125000 \mathrm{cal} / \mathrm{mole}$ for $\mathrm{ThO}_{2}$

Bubble radius $(\mathrm{cm})$

Average bubble radius $(\mathrm{cm})$

Radius of grain boundary bubble curvature $(\mathrm{cm})$

Half the distance between grain boundary bubbles $(\mathrm{cm})$.

Grain boundary bubble radius (cm) 


\section{NOMENCLATURE (Cont)}

\section{Symbol}

$$
<\mathrm{I}_{\mathrm{b}}>
$$

$\mathbf{R}_{\mathrm{b}}$

$\mathrm{r}_{\mathrm{c}}$

$\mathbf{r}_{\mathrm{d}}$

$\mathbf{r}_{\mathbf{e}}$

$<r_{e}>$

$\cdot \mathbf{R}_{\mathrm{g}}$

$r_{p}$

$r_{p}^{\prime}$

$\mathrm{T}$

$t_{n}$

$\mathrm{V}$

$a$

$\beta$

$\dot{\Gamma}$

$\gamma^{\circ}$

$\gamma_{\mathrm{Gb}}$

$\delta$

$\delta^{\prime}$

$\Delta t$

$\nabla \mathrm{T}$

$\epsilon$

$\eta$

$\lambda$

$\lambda^{\prime}$

\section{Definition}

Average grain boundary bubble radius ( $\mathrm{cm}$ )

$\frac{2}{\sqrt{14}} R_{g} \cdot(\mathrm{cm})$, grain face radius

Radius of grain corner bubble $(\mathrm{cm})$

Radius of collapsed vacancy loop assumed to represent damage cascade (cm)

Radius of grain boundary edge bubble $(\mathrm{cm})$

Average grain boundary edge bubble radius (cm)

Grain radius (cm)

Intragranular fábricated pore radius $(\mathrm{cm})$

Corner pore radius $(\mathrm{cm})$

Absolute temperature $\left({ }^{\circ} \mathrm{K}\right)$

Time for a bubble containing $\mathrm{n}$ atoms to coalesce (sec)

Grain boundary bubble volume $\left(\mathrm{cm}^{3}\right)$

1.587 (unitless)

$6.97 \times 10^{-23} \mathrm{~cm}^{3}$, van der Waals gas constant

Bubble jump frequency $\left(\mathrm{cm}^{-1}\right)$

626 ergs $/ \mathrm{cm}^{2}$, surface tension for $\mathrm{UO}_{2} ; 775$ ergs $/ \mathrm{cm}^{2}$ for $\mathrm{ThO}_{2}$

Grain boundary energy (ergs $/ \mathrm{cm}^{2}$ )

$\left(\frac{3 \beta}{4 \pi}\right)^{1 / 3}$

Distance from grain boundary $(10 \AA)$ in which grain boundary diffusion takes place

Time step (sec)

Temperature gradient $\left({ }^{\circ} \mathrm{C} / \mathrm{cm}\right)$

0.05 , size misfit parameter (unitless)

Number of vacancies knocked out of a pore per collision with fission fragment $3.86 \times 10^{-8} \mathrm{~cm}$ for $\mathrm{UO}_{2} ; 3.52 \times 10^{-8} \mathrm{~cm}$ for $\mathrm{ThO}_{2}$

Viable fission fragment length for causing displacements $\left(10^{-4} \mathrm{~cm}\right)$ 
NOMENCLATURE (Cont)

Symbol

$\mu$

$\nu$

$\xi$

$\xi^{\prime}$

$\rho^{\prime}$

$\rho_{b}$

$\tau$

$\varphi$

$\Omega$
$7.2 \times 10^{11}$ dynes $/ \mathrm{cm}^{2}$, shear modulus

Poisson's constant

$\left(\frac{\mathrm{kT}}{8 \gamma \pi}\right)\left(\frac{4 \pi}{3 \bar{\beta}}\right)^{1 / 3}$

Number of vacancies escaping two damage cascades

Dislocation density $\left(\mathrm{cm}^{-2}\right)$

Distance from center of grain face $(\mathrm{cm})$

Mean stay time of a lattice atom between two fission events (sec)

Argle bëtween grain boundary and bubble surface

$4.1 \times 10^{-23} \mathrm{~cm}^{3}$, atomic volume for $\mathrm{UO}_{2} ; 4.38 \times 10^{-23}\left(\mathrm{~cm}^{3}\right)$ for $\mathrm{ThO}_{2}$ 
A model was developed to predict in-pile fission gas swelling. gas release, and densification in oxide fuels. This model considers fission gas behavior at the grain interior, on the grain boundaries, and at grain boundary edges under conditions of total gas bubble destruction by fission fragments and partial gas bubble destruction. When gas bubble swelling on grain edges reaches 5 percent, it is assumed that gas tunnels form along the edges. Gas release takes place by migration of the gas in the grains and on the grain boundaries to the edge tunnels. Intergranular and intragranular densifications are considered. Densification takes place by vacancy boil-off due to thermal excitation and vacancy knockout by the passage of fission fragments through the pores. The migration rates of both vacancies and interstitials to pores are also calculated. Comparisons are made between the model and experimental data for swelling, gas release, and.densification and found to be in reasonable agreement in most cases.

\title{
A MODEL TO PREDICT SWELLING, GAS RELEASE, AND DENSIFICATION IN OXIDE FUELS \\ (AWBA Development Program)
}

\author{
C. C. Dollins
}

\section{INTRODUCTION}

This report describes a model for calculating swelling due to tission gas and solid fission products, gas release, and densification of fabricated porosity in oxide fuels: The model keeps track of the location of the gas in the fuel and assumes that gas migrates from the grain interior to grain boundaries, along grain boundaries to grain edges, and along grain edges to grain corners: Once the gas swelling due to bubbles on the grain edges and at the corners exceeds 5 percent, tunnels form along the grain edges and gas release occurs. There are seven regions or conditions in the fuel where gas behavior.is considered:

1. Small intragranular gas bubbles (radius, $r$ $<25 \AA$ ), which can be destroyed by a single fission fragment

2. Large intragranular gas bubbles $(r>25 \AA)$, which cannot be destroyed by a single fission fragment

3. Small grain boundary gas bubbles $\left(r_{b}\right.$ $<.25 \AA$ ), which ran be destroyed by a single fission frayment

4. Large grain boundary gas bubbles ( $r_{b}$ $>25 \AA$ ), which cannot be destroyed by a single fission fragment

5. Grain boundary edge bubbles which can always be destroyed, since they never get larger than the $25 \AA$ cutoff radius

6. Corner bubbles which can never be de. stroyed, since any gas knocked from them immediately funnels back to the grain corners along the grain boundaries

7. Tunnels along grain edges, which result in gas escape.

\section{MODEL DESCRIPTION}

\section{A. Grain Interior Gas Bubble Behav- ior for Bubble Radius $<25 \mathrm{~A}$}

During fissioning of ${ }^{235} \mathrm{U}$, gas is produced at the rate 0.3 atom per fission event, and during fissioning of ${ }^{233} \mathrm{U}$ at the rate 0.34 atom per fission event. This rate is treated as an atom fraction so that gas is produced for ${ }^{235} \mathrm{U}$ in the model at the rate

$$
\dot{a}=0.3 \dot{f} \Omega
$$

where

$$
\begin{aligned}
& \dot{f}=\text { the fission rate in fissions } / \mathrm{cm}^{3} \text { second } \\
& \Omega=\text { the atomic volume }\left(4.1 \times 10^{-23} \mathrm{~cm}^{3}\right) .
\end{aligned}
$$

It is assumed that the tission gas is randomly or uniformly produced and is thermodynamically insoluble in $\mathrm{UO}_{2}$. The gas forms a stable bubble nucleus when two gas atoms meet. The bubbles increase in size by coalescing. The bubble lifetime is limited to the time between two fissiun everuts in the same region, $\tau$, which is given in Reference 1 by

$$
\tau=\left(1.0 \times 10^{5} \Omega \dot{\mathrm{i}}\right)^{-1}
$$

It is then assumed that the gas bubbles are complotely destroyed and the gas is driven randomly back into solution. Such a model will not be correct if the bubbles are larger than $\mathrm{r}=25 \AA$ because a single fission event would be unable to destroy the bubbles. Consequently, the model is limited to low temperatures where bubble migration is 
sufficiently slow to prevent the bubble radius from becoming larger than $25 \AA$.

In order to calculate swelling and long-range migration, it is necessary to calculate the average bubble radius and the number of bubbles present.

It is assumed that the gas pressure within a bubble is in equilibrium with the surface tension so that van der $W$ aals gas law can be written approximately as

$$
\frac{2 \gamma}{r}\left(\frac{4}{3} \pi r^{3}-r \beta\right)=n k T .
$$

where

$$
\begin{aligned}
\mathrm{r}= & \text { bubble radius } \\
\gamma= & \text { surface tension (not temperature depen- } \\
& \text { dent) } \\
\mathrm{n}= & \text { number of gas atoms in the bubble } \\
\beta= & \mathrm{van} \text { de } \mathrm{W} \text { a a } \mathrm{s} \text { constant }(6.97 \\
& \left.\times 1 \mathrm{n}^{-23} \mathrm{~cm}^{3}\right) \\
\mathrm{k}= & \text { Boltzmann's constant }\left(1.38 \times 10^{-16}\right) \\
\mathrm{l}^{\prime}= & \text { absolute temperature. }
\end{aligned}
$$

For purposes of this report, it is necessary to solve Equation (3) for r. At low temperatures and small n (which is expected for a model with complete bubble destruction), $\mathrm{r}$ is given by

$$
\mathrm{r}=\left(\frac{3 \mathrm{n} \beta}{4 \pi}\right)^{1 / 3}+\frac{\mathrm{nkT}}{8 \gamma \pi}\left(\frac{4 \pi}{3 \mathrm{n} \beta}\right)^{1 / 3}
$$

or

$$
\simeq \delta \mathrm{n}^{1 / 3}+\xi \mathrm{n}^{2 / 3},
$$

where the second term is smaller than the first.

To calculate the number of atnms in a bubble, it will be assumed that immediately after a fission tragment passes through a region the isolated gas d coms in that region migrate until they collide with one another, forming two-atom bubbles. The twoatom bubbles migrate until they collide, forming four-atom bubbles, etc. It will be assumed that the bubbles lie on a simple cubic "bubble lattice" with a lattioc spacing of 21 . The average number of jumps that a bubble makes before coalescence (Refcrence 2) is

$$
\bar{n}=1.52 / C^{\prime},
$$

where $C^{\prime}$ is the probability that a bubble lattice site is occupied by a bubble. If $\mathbf{N}^{\prime}$ is the number of bubbles per unit volume then $C^{\prime}=N^{\prime}(2 r)^{3}$ and $\bar{n}$ $=1.52 / \mathrm{N}^{\prime}(2 \mathrm{r})^{3}$. The jump frequency of the bubbles on the "bubble lattice" is

$$
\Gamma=6 \mathrm{D}_{\mathrm{b}} /(2 \mathrm{r})^{2} \text {, }
$$

where $D_{b}$ is the bubble diffusion coefficient. The relative jump frequency for two bubbles is twice that given by Equation (6). From Reference 3, the time for a bubble of a given size to coalesce is given by

$$
t_{n}=\frac{\bar{n}}{\Gamma}=\frac{1.52(2 r)^{2}}{2 N^{\prime}(2 r)^{3} 6 D_{b}}=\frac{0.063}{N^{\prime} r D_{b}}
$$

The time for a bubble containing $\mathrm{n}$ atoms to coalesce is then

$$
\mathrm{t}_{\mathrm{n}}=0.063 \mathrm{n} / \mathrm{mr} \mathrm{D}_{\mathrm{b}},
$$

where $\mathrm{m}$ is the number of gas atoms in a unit volume. If $\tau$ is the time between collisions with a fission fragment given by Equation (2), then $\tau$ is also the total time that the gas bubbles can migrate and

$$
T=t_{1}+t_{2} t_{4}+t_{8}+\ldots+t_{N^{\prime \prime}},
$$

where $\mathbf{N}^{\prime \prime}$ is the number of gas atoms in a bubble just before destruction. Fquation (9) can be writley

$$
\tau=\sum_{j=0}^{\ln N^{\prime \prime} / \ln 2} t_{2} j
$$

Using the gas bubble diffusion coefficient derived from Reference 4,

$$
D_{b}=A / r^{3}\left(\mathrm{~cm}^{2} / \mathrm{sec}\right) \text {, }
$$

where $\AA=1.19 \times 10^{-22} \exp \left(-100000 / \mathrm{Kl}^{\prime}\right)$ $\mathrm{cm}^{5} / \mathrm{sec}$, Equation ( 8 ) becomes

$$
h_{n}=0.063 \mathrm{nr}^{2} / \mathrm{mA} \text {. }
$$

From Equation (4),

$$
\mathrm{r}^{2}=\delta^{2} \mathrm{n}^{2 / 3}+2 \delta \xi \mathrm{n},
$$

su that

$$
t_{\mathrm{a}}=\frac{0.063}{m \bar{A}}\left(\delta^{2} \mathrm{n}^{5 / 3}+2 \delta \xi \mathrm{n}^{2}\right)
$$

From Reference 3, Equation (10) then hecomes

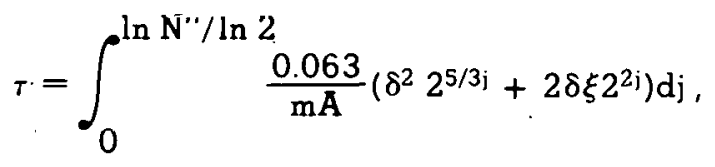

or

$$
\tau=\frac{0.063 \delta}{\mathrm{m} \AA \ln 2}\left[3 / 5 \delta \mathrm{N}^{\prime \prime 5 / 3}+\xi \mathrm{N}^{\prime \prime 2}\right]
$$


Solving for $\mathrm{N}^{\prime \prime}$ by Newton's approximation per Reference 3 yields

$$
\mathrm{N}^{\prime \prime}=5.72\left(\frac{\tau \mathrm{mA}}{\delta^{2}}\right)^{3 / 5}-10.2 \frac{\xi}{\delta}\left(\frac{\tau \mathrm{mA}}{\delta^{2}}\right)^{4 / 5} .
$$

The average number of atoms in a bubble, for the time interval $\tau$, is

$$
<\mathrm{N}>=\frac{1}{\tau} \int_{0}^{\tau} \mathrm{N}^{\prime \prime} \mathrm{dt}
$$

Integrating this (Reference 3) gives

$$
\begin{aligned}
<\mathrm{N}>= & 6.34 \frac{\mathrm{l}}{\beta^{2 / 5}}(\tau \mathrm{mA})^{3 / 5} \\
& -1.26 \frac{\mathrm{kT}}{\gamma \beta^{6 / 5}}(\tau \mathrm{m} A)^{4 / 5}
\end{aligned}
$$

where the values of $\delta$ and $\xi$ have been substituted into Equation (16). From Equation (4) the average bubble radius over the time step (Reference 3 ) is given by

$$
\begin{aligned}
<_{\mathrm{I}}>= & \left(\frac{3<\mathrm{N}>\beta}{4 \pi}\right)^{1 / 3} \\
& +\frac{<\mathrm{N}>\mathrm{kT}}{8 \gamma \pi}\left(\frac{4 \pi}{3<\mathrm{N}>\beta}\right)^{1 / 3}
\end{aligned}
$$

and the swelling is given by

$$
\left.\left.\frac{\Delta \mathrm{V}}{\mathrm{V}}\right|_{\mathrm{m}}=\frac{\mathrm{m}}{<\mathrm{N}>} 4 / 3 \pi<\mathrm{r}\right\rangle^{3} .
$$

The first term in Equation (17) gives the number of gas atoms accumulated in a bubble if the gas is completely a van der Waals solid. The second term in Equation (17) is tho deviation from solid or frozen gas due to high temperature or low pressure, $P$; that is, small $P=2 \gamma / \mathrm{r}$ due to a large bubble radius. The fact that bubble growth is limited by fission events means that the second term in Equation (17) is much smaller than the first. The same holds true for Equation(18). Using Equations (17) and (18), the long-range migration of the gas from the grain interior to the grain boundaries can be calculated.

Using the low temperature, small bubble approximation, Equation (18) is

$$
<\mathrm{I}>=(3<\mathrm{N}>\beta / 4 \pi)^{1 / 3}
$$

and Equation (17) becomes

$$
<\mathrm{N}>=6.34 \frac{1}{\beta^{2 / 5}}(\tau \mathrm{mA})^{3 / 5}
$$

so that

$$
<\mathrm{r}>=1.14 \cdot\left(\frac{\beta \tau A}{\Omega}\right)^{1 / 5} C^{1 / 5},
$$

where $C=m \Omega$ is the atom fraction gas concentration in the matrix. The average gas diffusion coefficient in the matrix is obtained by substituting $\langle\mathrm{r}\rangle$. from Equation (20) into Equation (11):

$$
D=\frac{A^{2 / 5}}{1.5 !}\left(\frac{\Omega}{\beta \tau}\right)^{3 / 5} \frac{1}{C^{3 / 5}} .
$$

In this work grains are treated as spheres of radius $\rho=R_{g}$, where $\rho$ is the distance from the center of the grain. Gas migration to the grain boundaries is calculated by solving the transport equation in spherical coordinates:

$$
\frac{\partial \mathrm{C}}{\partial \mathrm{t}}=\frac{1}{\rho^{2}} \frac{\partial}{\partial \rho}\left(\rho^{2} \mathrm{D} \frac{\partial \mathrm{C}}{\partial \rho}\right)+\dot{\mathrm{a}} .
$$

where $C=m \Omega$ is the gas atom concentration in atom fraction and $\dot{a}$ is the gas atom generation rate.

It is assumed that the grain boundaries are perfect traps so that $C\left(\rho=R_{g}\right)=0$. At these temperatures, the equilibrium gas concentration at the boundaries is on the order of $10^{-22}$ (units of atom fraction), which for purposes of this report is essentially zero. The other boundary condition for Equation (22) is that

$$
\left.\frac{\partial C}{\partial \rho}\right|_{\rho=0}=0 .
$$

Initially, C = 0; therefore, from Equation (21), D is infinite. This is unreasonable. $\mathrm{D}$ cannot exceed $D_{g}$ where $D_{g}$ is the diffusion coefficient of an isolated gas atom (Reference 5) given by

$$
\begin{gathered}
D_{g}= \\
\quad .6 \times 10^{-6} \exp (-71500 / \mathrm{RT}) \\
+\frac{\left(2.5 \times 10^{-7}\right)^{2}}{6 \tau}
\end{gathered}
$$

In the presence of a temperature gradient, $D$ is augumented by $D_{\text {eff }}$. Both $D_{q}$ and $D_{\text {eff }}$ are functions of operating conditions. $D_{\text {eff }}$ is given by

$$
\mathrm{D}_{\mathrm{ell}}=\frac{2 \times 10^{5} \mathrm{~A} \pi \nabla \mathrm{TR}}{9 \mathrm{RT}^{2} \Omega},
$$

where $\nabla \mathrm{T}$ is the temperature gradient in $\mathrm{C} / \mathrm{cm}$ 


\section{B. Intragranular Bubble Behavior When the Bubble Radius $>25 \AA$}

If the bubble radius is $>25 \AA$, then the gas bubbles are too large to be destroyed by a fission fragment and they grow. However, the fragments can still knock gas out of the bubbles and do it at the rate (Reference 6 ) $n / \tau$ where $n$ is the number of gas atoms in the bubble. The gas that is knocked out can flow back to the bubbles at the rate $4 \pi \mathrm{D}_{\mathrm{g}} \mathrm{C}_{\mathrm{I}} \mathrm{N}_{\mathrm{o}} \mathrm{B}^{\prime} \mathrm{n}^{1 / 2}$, where $\mathrm{D}_{\mathrm{g}}$ is the gas atom diffusion coefficient, $C_{I}$ is the concentration of single gas atoms in atom fraction, $N_{\circ}$ is the number of lattice atoms per unit volume, and $B^{\prime}$ is a constant relating the number of atoms in a bubble, $n$, to the bubble radius, $r$, such that

$$
\mathrm{r}=\mathrm{B}^{\prime} \mathrm{n}^{1 / 2}
$$

Hydrostatic stresses are not considered in Equation (23). They are factured in later. Equation (23) can be derived from the ideal gas law as follows:

$$
\left(\frac{2 \gamma}{r}\right) \frac{4}{3} \pi r^{3}=n k T .
$$

where the first factor in parentheses is the gas pressure in the bubble, and the second factor on the left is the bubble volume. Equation (24) can be written

$$
\frac{8 y \pi r^{2}}{3}=n k T \text {. }
$$

Equation (25) can be written

$$
\mathbf{r}=\left(-\frac{3 \mathrm{k} T}{8 \gamma \pi}\right)^{1 / 2} \mathbf{n}^{1 / 2}
$$

Therefore,

$$
\mathrm{B}^{\prime}=\left(\frac{3 \mathrm{kT}}{8 \gamma \pi}\right)^{1 / 2} .
$$

In deriving Equations (23) and (27), the ideal gas law for the larger bubbles was assumed in urder to calculate the number of atoms in a bubble. Once that is known, van der Waals gas law is used to calculate the size of the bubble. This is an approximate way of taking into account external pressures, which are discussed later in this section.

The change in the concentration of single gas atoms is given in Reference 7 by

$$
\begin{aligned}
\frac{d C_{I}}{d t}= & 0.3 \dot{f} \Omega+\frac{N^{\prime} n \Omega}{\tau} \\
& -4 \pi D_{g} C_{l} N^{\prime} B^{\prime} n^{1 / 2},
\end{aligned}
$$

where $\mathrm{N}^{\prime}$ is the number of bubbles per unit volume. Under conditions of interest, the isolated single gas atoms will be in steady state so that $\mathrm{dC}_{\mathrm{I}} / \mathrm{dt}$ $=0$. Also $\mathrm{N}^{\prime} \mathrm{n} \Omega / \tau>0.3 \dot{\mathrm{f}} \Omega$ or $0.34 \dot{\mathrm{i}} \Omega$ for ${ }^{233} \mathrm{U}$ so that from Reference ?, Equation (28) becomes

$$
\frac{N^{\prime} n \Omega}{\tau}=4 \pi D_{g} C_{I} N^{\prime} B^{\prime} n^{1 / 2}
$$

Solving Equation (29) for $C_{I}$ per Reference 7 gives

$$
\mathrm{C}_{\mathrm{I}}=\frac{\mathrm{n}^{1 / 2} \Omega}{\tau 4 \pi \mathrm{D}_{\mathrm{g}} \mathrm{B}^{\prime}} .
$$

From Reference 7, the change in the number of gas atoms in a bubble with respect to time due to single gas atom behavior is given by

$$
\frac{\mathrm{dn}}{\mathrm{dt}}=4 \pi \mathrm{D}_{\gamma} \mathrm{C}_{\mathrm{l}} \mathrm{B}^{\prime} \mathrm{N}_{\odot} \mathrm{u}^{1 / 2}-\frac{\mathrm{n}}{\tau} .
$$

where $N_{0}$ is the number of lattice sites per unit volume. Equation (31) is the change in the number of gas atoms per unit time due solely to behavior of single gas atoms. The number of gas atoms in a bubble can also increase due to coalescence of the bubbles. It was previously shown that the time for two bubbles containing $\mathrm{n}$ atoms to coalesce (Reference 3 ) is

$$
\mathrm{t}_{\mathrm{n}}=\frac{0.063 \mathrm{r}^{2}}{\mathrm{~N}^{\prime} \mathrm{A}}=\frac{0.063 \mathrm{~B}^{2} \mathrm{n}}{\mathrm{N}^{\prime} \mathrm{A}}
$$

therefore,

$$
\frac{\mathrm{dn}}{\mathrm{dt}}=\frac{2 \mathrm{n} \cdot \mathrm{n}}{\mathrm{t}_{\mathrm{n}}}=15.87 \frac{\mathrm{N}^{\prime} \mathrm{A}}{\mathrm{B}^{\prime 2}}
$$

is the rate of change of gas in a bubble due to coalescence. The total rate of change (Reforence (l) is the sum of Erquatinns (31) and (33),

$$
\frac{d n}{d t}-15.07 \frac{N^{\prime} A}{B^{\prime 2}}+4 \pi I_{g} \bar{C}_{1} B^{\prime} N_{o} n^{1 / 2}-\frac{n}{\tau} .
$$

From conservation of gas,

$$
\mathbf{N}^{\prime}=\frac{\mathrm{m}-\mathrm{C}_{\mathrm{I}} \mathrm{N}_{\mathrm{o}}}{\mathbf{n}} \text {. }
$$

Equations (30) and (35) allow $C_{1}$ and $N^{\prime}$ lu be defined, and therefore Equation (34) per Reference "7 can be written

$$
\frac{\mathrm{dn}}{\mathrm{d} \mathrm{t}}=\frac{15.87 \AA}{\mathrm{B}^{\prime 2}}\left[\frac{\mathrm{C}}{\mathrm{n} \Omega}-\frac{1}{\mathrm{n}^{1 / 2} \tau 4 \pi \mathrm{D}_{\mathrm{g}} \mathrm{B}^{\prime}}\right],
$$


Equation (36) does not allow for the nucleation of new gas bubbles. As the bubbles grow, the isolated gas atom concentration increases according to Equation (30). The isolated gas concentration cannot exceed that necessary to nucleate new permanent gas bubbles. The number of gas atoms in a bubble of the critical size (i.e., that which will just be able to withstand an encounter with a fission fragment) is given by solving van der Waals equation using as the critical radius the $25 \AA$ value from Reference 7 quoted earlier:

$$
\mathrm{n}_{\mathrm{c}}=\frac{8 \gamma \pi\left(2.5 \times 19^{-7}\right)^{2}}{3\left(\mathrm{kT}+\frac{2 \gamma \beta}{2.5 \times 10^{-7}}\right)}
$$

From Reference 7, putting $n_{c}$ into Equation (17) and dropping the second term on the right-hand side of Equation (17), which is small compared to the first term, yields

$$
\mathrm{n}_{\mathrm{c}} \cong \frac{6.34}{\beta^{2 / 5}}\left(\tau \mathrm{C}_{\mathrm{c}} \mathrm{N}_{\circ} \AA\right)^{3 / 5}
$$

where $\mathrm{C}_{\mathrm{c}}$ is the critical concentration of isolated gas atoms beyond which nucleation of permanent bubbles will occur, thereby reducing the gas atom concentration back to $C_{c}$. Solving Equation (38) for $\mathrm{C}_{\mathrm{c}}$ (Reference 7 ) gives

$$
C_{c}=\frac{4.6 \times 10^{-2}}{\tau N_{o} \AA}\left(n_{c} \beta^{2 / 5}\right)^{5 / 3} .
$$

From Reference 7, setting $C_{1}$ equal to $C_{c}$ and substituting into Equation (34) gives

$$
\begin{aligned}
\frac{\mathrm{dn}}{\mathrm{dt}}= & \frac{15.87 A N_{\circ}}{\mathrm{B}^{\prime 2}}\left(\frac{\mathrm{C}-\mathrm{C}_{\mathrm{c}}}{\mathrm{n}}\right) \\
& +4 \pi \mathrm{D}_{\mathrm{g}} \mathrm{C}_{\mathrm{c}^{\prime}} \mathrm{B}^{\prime} \mathrm{N}_{\mathrm{o}} \mathrm{n}^{1 / 2}-\frac{\mathrm{n}}{\tau} .
\end{aligned}
$$

Equation (40) is difficult to solve even by numerical methods; however, the steady-state equation obtained by setting $\mathrm{dn} / \mathrm{dt}=0$ is much easier to solve. It must be shown that $d n / d t=0$ is valid. If it is valid at low temperatures, then it must be valid at higher temperatures where bubble and gas diffusion are much more rapid. At $1300^{\circ} \mathrm{C}$ (at lower temperatures large bubbles do not form) and for a fission rate of $10^{13}$ fissions $/ \mathrm{cm}^{3}$ second and using the values of the parameters given in the Nomenclature, $C_{c}$ is $3.89 \times 10^{-3}$ and $n_{c}$ is 579. At a depletion of $4 \times 10^{20}, \mathrm{C}$ is equal to $5.59 \times 10^{-3}$ for $\dot{f}=10^{13}$ tissions $/ \mathrm{cm}^{3}$ second. Using $\mathrm{n}$ equal to $\mathrm{n}_{\mathrm{c}}$ the first term on the right-hand side of Equation (40) is equal to 0.0373 and the second term is 0.150 . At equilibrium when $\mathrm{dn} / \mathrm{dt}=0$, the first term on the right-hand side is equal to 0.00093 and the second term is equal to 0.951 . Consequently, under these conditions the first term on the right-hand side can be ignored. From Reference 7 the solution of the remaining equation,

$$
\frac{\mathrm{dn}}{\mathrm{dt}}=4 \pi \mathrm{D}_{\mathrm{g}} \mathrm{C}_{\mathrm{c}} \mathrm{B}^{\prime} \mathrm{N}_{\mathrm{o}} \mathrm{n}^{1 / 2}-\frac{\mathrm{n}}{\tau}
$$

is.

$$
\begin{aligned}
\mathrm{n}_{2}= & {\left[4 \pi \mathrm{D}_{\mathrm{g}} \mathrm{C}_{\mathrm{c}} \mathrm{B}^{\prime} \mathrm{N}_{\mathrm{o}} \tau\right.} \\
& -\left(4 \pi \mathrm{D}_{\mathrm{g}} \mathrm{C}_{\mathrm{c}} \mathrm{B}^{\prime} \mathrm{N}_{\mathrm{o}} \tau\right. \\
& \left.\left.-\mathrm{n}_{l}^{1 / 2}\right) \exp (-\Delta t / 2 \tau)\right]^{2},
\end{aligned}
$$

where $n_{1}$ is the initial number of gas atoms in the bubble and $n_{2}$ is the number of gas atoms in the bubble $\Delta t$ later. The value $n_{2}$ is reached on the order of $2 \tau$, which for a fission rate of $10^{13}$ fissions $/ \mathrm{cm}^{3}$ second is about seven hours: In seven hours the depletion is going to change very little and hence $C$ is going to change very little; thus, setting $\mathrm{dn} / \mathrm{dt}$ equal to zero is a good approximation. In the initial stages $\mathrm{n}$ is very small, making the first term on the right-hand side of Equation (40) large. This produces an even more rapid advance to steady state. From Reference 7, Equation (40) now becomes

$$
\begin{gathered}
\frac{15.87 \AA N_{o}}{B^{\prime 2}}\left(\frac{C-C_{c}}{n}\right)+4 \pi D_{g} C_{c} B^{\prime} n^{1 / 2} N_{o} \\
-\frac{n}{t}=0 .
\end{gathered}
$$

The roots of Equation (43) can be found analytically but with difficulty. The roots can be found easily on a computer using the Newton-Raphson method. Setting the left-hand side of Equation (43) equal to $F(n)$, an iteration scheme can be written

$$
\mathbf{n}_{1}=\mathbf{n}_{0}-\frac{\mathbf{F}\left(\mathbf{n}_{0}\right)}{\mathbf{F}^{2}\left(\mathbf{n}_{\mathrm{o}}\right)}
$$

where $F^{\prime}\left(n_{0}\right)$ is the first derivative of $F$ with respect to $n$ evaluated at $n_{0}$. The initial value of $n_{0}$ comes from the previous time step. Once $n$, the number of gas atoms in a bubble is known, the bubble radius is calculated from van der Waals gas law. The number of bubbles per unit volume is given by

$$
\mathbf{N}^{\prime}=\frac{\mathrm{N}_{\mathrm{u}}\left(\mathrm{C}-\mathrm{C}_{\mathrm{e}}\right)}{\mathrm{n}}
$$

The swelling is given by

$$
\left.\frac{\Delta V}{V}\right|_{m}=\frac{4}{3} \pi r^{3} N^{\prime}+\beta C_{c} N_{o}
$$


The average gas diffusion coefficient is given by

$$
D=\frac{\frac{A}{r^{3}} N^{\prime} n+C_{c} N_{o} D_{g}}{N_{o} C}+D_{e f f} .
$$

The diffusion coefficient given by Equation (47) is that used in Equation (22) to calculate the amount of gas that migrates to the grain boundaries and the amount remaining in the interior of the grains. As before, $D$ is not allowed to exceed $D_{g}$.

In the computer program, the small matrix gas bubble and large matrix gas bubble calculations are combined.

For the large bubbles ( $r>25 \AA$ ), the number of atoms in the bubbles is first calculated and then their radii using van der Waals gas law:

$$
\frac{4}{3} \pi \mathrm{rr}^{4}+\gamma \frac{\gamma}{3} \pi \mathrm{r}^{3}-\mathrm{r}(\operatorname{Pn} \beta+\mathrm{nkT})-2 \gamma \mathrm{n} \beta=0
$$

where $P$ is the external pressure (dynes $/ \mathrm{cm}^{2}$ ).

The rate that gas leaves the matrix and migrates to the grain boundary, $\dot{a}_{h \prime}$ is given by

$$
\dot{a}_{b}=\left(\dot{a}-\frac{\Delta C}{\Delta t}\right) \frac{2 R_{g}}{3 \gamma},
$$

where

$$
\begin{aligned}
\gamma= & \text { atomic jump distance } \\
\Delta \mathrm{C}= & \text { change in the average gas concentration } \\
& \text { in the grain interior, in units of atom frac- } \\
& \text { tion } \\
\Delta \mathrm{t}= & \text { time step over which } \Delta \mathrm{C} \text { is measured. }
\end{aligned}
$$

The average gas concentration in the grain interior is given by

$$
<\mathrm{C}>=\frac{1}{\frac{4}{3} \pi \mathrm{R}_{\mathrm{g}}^{3}} \int_{0}^{\mathrm{R}_{\mathrm{g}}} \mathrm{C}(\rho) 4 \pi \rho^{2} \mathrm{~d} \rho .
$$

Grain boundary swelling and gas migration can now be calculated.

\section{Grain Boundary Gas Bubble Swelling and Gas Migra- tion for Bubble Radius $<25 \AA$}

A gas bubble on a grain boundary will be lens shaped due to the grain boundary energy, assuming it approximates an equilibrium shape. The angle the bubble makes at the grain boundary, $\varphi$, is related to the grain boundary energy by the equation

$$
\cos \varphi=\frac{\gamma_{\mathrm{Gb}}}{2 \gamma}
$$

If $r_{b}$ is the radius of the bubble on the grain boundary and $\bar{R}$ is the actual radius of curvature of the bubble, then

$$
\dot{\mathrm{r}}_{\mathrm{b}}=\overline{\mathrm{R}} \sin \varphi .
$$

Assuming that the gas pressure within the bubble equilibrates with the surface tension, then $P$ $=2 \gamma / \mathrm{R}$, so that

$$
\mathrm{P}=\frac{2 \gamma \sin \varphi}{\mathrm{r}_{\mathrm{b}}}
$$

The volume of the bubble is given by

$$
\mathrm{V}=\frac{2}{3} \pi r_{\mathrm{b}}^{3} \frac{(1-\cos \varphi)(2+\cos \varphi)}{\sin \varphi(1+\cos \varphi)}
$$

or

$$
\mathrm{V}=\boldsymbol{\alpha} \Gamma_{\mathrm{b}}^{3}
$$

van der Waals gas law is given hy

$$
\mathrm{P}\left(\mathrm{V}-\mathrm{n}_{\mathrm{b}} \beta\right)=\mathrm{n}_{\mathrm{b}} \mathrm{kT} \text {, }
$$

where $\mathrm{n}_{\mathrm{b}}$ is the number of gas atoms in the bubble. Substituting Equations (50) and (51) into (52). gives

$$
\frac{2 \gamma \sin \varphi}{\mathrm{r}_{\mathrm{b}}}\left(\alpha \mathrm{r}_{\mathrm{b}}^{3}-\mathrm{n}_{\mathrm{b}} \beta\right)=\mathrm{n}_{\mathrm{b}} \mathrm{kT} .
$$

From Reference 7, solvinq Equation (53) for $r_{b}$ in the case of small bubbles gives

$$
\mathbf{r}_{\mathrm{b}} \cong\left(\frac{\beta}{\alpha}\right)^{1 / 3} \mathbf{n}_{\mathrm{h}}^{1 / 3}+\frac{\mathbf{n}_{\mathrm{b}} \mathrm{kT}}{6 \gamma \sin \psi \dot{u}}\left(\frac{\alpha}{\mathrm{u}_{\mathrm{b}} \beta}\right)^{1 / 3},
$$

which can be written

$$
\mathrm{r}_{\mathrm{b}} \cong \delta_{\mathrm{b}} \mathrm{n}_{\mathrm{b}}^{1 / 3}+\xi_{\mathrm{b}} \mathrm{n}_{\mathrm{b}}^{2 / 3}
$$

Fission fragments are able to knock gas atoms from the grain boundaries but only for distances of approximately $15 \AA$; because of the extensive nature of the grain boundary it is expected that the gas atoms will return to the boundary and not be able to escape. Consequently, gas buildup on the buundary bocomos quite large. As in the case of the grain interior, it is assumed that grain boundary bubbles obey van der Waals gas law and that they can be completely destroyed by a single fission fragment.

In order to calculate bubble growth on the boundary, it is necessary to develop a technique similar to that used for grain interior.

As before, assume a square "bubble lattice" on the grain boundary with lattice parameter $2 r_{b}$, 
where $r_{b}$ is the grain boundary bubble radius. The concentration, $\mathrm{C}_{\mathrm{b}}^{\prime}$, of gas bubbles is the fraction of sites occupied by bubbles. If $S_{n}$ is the number of new sites visited after $n_{b}^{i}$ jumps, then the number of jumps to coalescence, $\overline{\mathbf{n}}_{\mathrm{b}}^{\prime}$, is calculated by solving the equation

$$
l=\int_{0}^{\bar{n}_{b}^{\prime}} b \frac{\partial S_{n}}{\partial n_{b}^{\prime}} C_{b}^{\prime} d n_{b}^{\prime}
$$

For random walk confined to a plane, Dvoretzky and Erdos (Reference 8) found

$$
\mathrm{S}_{\mathrm{n}}=\pi \mathrm{n}_{\mathrm{b}}^{\prime} / \ln \mathrm{n}_{\mathrm{b}}^{\prime},
$$

where $n_{b}^{\prime}$ is a very large number. For $n_{b}^{\prime}$ less than about 23, Equation (57) indicates that the number of new sites visited is greater than the number of jumps and so Equation (57) is not adequate for the case herein, where a small number of jumps is expected. For use in this report, Equation (57) is approximated by

$$
\mathrm{S}_{\mathrm{n}}=\mathrm{n}_{\mathrm{b}}^{0.89},
$$

which agrees with Equation (57), within 5 percent over nearly four orders of magnitude up to $n_{b}^{\prime}$ $=10^{6}$. Equation (58) also has the benign result of giving one new site visited by the first jump, unlike Equation (57). Substituting $S_{n}$ from Equation (58) into Equation (56) and solving yields

$$
\mathrm{n}_{\mathrm{b}}^{\prime}=\mathrm{C}_{\mathrm{b}}^{\prime-1.12}
$$

as the number of jumps a gas bubble must make to coalesce with another gas bubble of the same size. Since

$$
\mathrm{C}_{\mathrm{b}}^{\prime}=\mathrm{N}_{\mathrm{b}}^{\prime}\left(2 \mathrm{r}_{\mathrm{b}}\right)^{2}
$$

where $\mathrm{N}_{b}^{\prime}$ is the number of bubbles per unit area of grain boundary,

$$
\mathrm{n}_{\mathrm{b}}^{\prime}=\left[\mathrm{N}_{\mathrm{b}}^{\prime}\left(2 \mathrm{r}_{\mathrm{b}}\right)^{2}\right]^{-1.12} \text {. }
$$

The relative jump frequency between two bubbles confined to motion in a plane is

$$
f_{b}=8 D_{b} /\left(2 r_{b}\right)^{2}
$$

As before, it can be shown from Reference 3 that the lifetime of a bubble containing $\mathrm{n}_{\mathrm{b}}$ atoms is

$$
t_{n}=\frac{\bar{n}_{b}^{\prime}}{f_{b}}=\frac{n_{b}^{1.12} r_{b}^{2.76}}{9.45 A m_{b}^{1.12}}
$$

where Equation (11) is assumed, and $m_{b}$ is the number of gas atoms per unit area of boundary. The bubble radius, $I_{b}$, is given by Equation (55) and $r_{b}^{2.76}$ is given by

$$
\mathrm{r}_{\mathrm{b}}^{2.76}=\delta_{\mathrm{b}}^{2.76} \mathrm{n}_{\mathrm{b}}^{0.92}+2.76 \delta_{\mathrm{b}}^{1.76} \xi_{\mathrm{b}} \mathrm{n}_{\mathrm{b}}^{1.25}
$$

From Reference 3, Equation (60) then becomes

$$
t_{n}=\frac{\delta_{b}^{1.76}}{9.45 A_{b}^{1.12}}\left(\delta_{b} n_{b}^{2.04}+2.76 \xi_{b} n_{b}^{2.37}\right)
$$

After integrating as in Equation (14a), it is found that the time interval, $\tau$, for grain boundary bubbles to grow until they contain $\mathrm{N}_{\mathrm{b}}$ atoms (Reference 3) is

$$
\tau=\frac{\delta_{\mathrm{b}}^{1.76}}{9.45 \mathrm{Am}_{\mathrm{b}}^{1.12}}\left[\frac{\delta_{\mathrm{b}}}{2.04} \frac{\mathrm{N}_{\mathrm{b}}^{2.04}}{\ln 2}+\frac{1.165}{\ln 2} \xi_{\mathrm{b}} \mathrm{N}_{\mathrm{b}}^{2.37}\right]
$$

From Reference 3, solving for $\mathrm{N}_{b}$ by Newton's approximation yields

$$
\begin{aligned}
\mathbf{N}_{\mathrm{b}}= & \left(\frac{13.36 A \mathrm{~m}_{\mathrm{b}}^{1.12} \tau}{\delta_{\mathrm{b}}^{2.76}}\right)^{0.49} \\
& -1.164 \frac{\xi_{\mathrm{b}}}{\delta_{\mathrm{b}}}\left(\frac{13.36 A \mathrm{~m}_{\mathrm{b}}^{1.12} \tau}{\delta_{\mathrm{b}}^{2.76}}\right)^{0.65}
\end{aligned}
$$

From Reference 3, averaging over a time interval, $\tau$, yields

$$
\begin{aligned}
<\mathrm{n}_{\mathrm{b}}>=2.39 & \left(\frac{A \mathrm{~m}_{\mathrm{b}}^{1.12} \tau}{\delta_{\mathrm{b}}^{2.76}}\right)^{0.49} \\
& -3.8 \frac{\xi_{\mathrm{b}}}{\delta_{\mathrm{b}}}\left(\frac{\AA \mathrm{m}_{\mathrm{b}}^{1.12} \tau}{\delta_{\mathrm{b}}^{2.76}}\right)^{0.65}
\end{aligned}
$$

as the average number of atoms in a grain boundary bubble where $m_{b}$ is the number of gas atoms on the grain boundary per unit area. The second term on the right-hand side of Equation (62) is much smaller than the first. The average grain boundary hubble radius, $\left\langle r_{b}\right\rangle$, is given by substituting $\left\langle\mathrm{n}_{\mathrm{b}}\right\rangle$ into Equation (5), and the average grain boundary gas diffusion coefficient, $D_{b}$, is given by substituting $\left\langle\mathrm{r}_{\mathrm{b}}\right\rangle$ into Equation (11):

$$
\mathrm{D}_{\mathrm{b}}=\frac{\AA}{\left.<\mathrm{r}_{\mathrm{b}}\right\rangle^{3}}
$$


With knowledge of the long-range grain boundary gas diffusion coefficient, migration of the gas in the grain boundaries to grain boundary edges can be calculated. If it is assumed that the grains are tetrakaidecahedrons and, if it is further assumed that each of the fourteen faces has equal area, then the area of one grain face is equal to $4 \pi \mathrm{R}_{\mathrm{g}}^{2} / 14$. The radius of the face is given by

$$
R_{b}=\frac{2}{\sqrt{14}} R_{g},
$$

where $R_{g}$ is the grain radius.

It is assumed that the grain edges are pertect traps for the grain faces so that the concentration at the grain edges is equal to zero. Gas motion on the grain faces can be determined by solving the transport equation using polar coordinates:

$$
\frac{\partial \mathrm{C}_{\mathrm{b}}}{\partial \mathrm{t}}=\frac{1}{\rho_{\mathrm{b}}} \frac{\partial}{\partial \rho_{\mathrm{b}}}\left(\rho_{\mathrm{b}} \mathrm{D}_{\mathrm{b}} \frac{\partial \mathrm{C}_{\mathrm{b}}}{\partial \rho_{\mathrm{b}}}\right)+\dot{\mathrm{a}}_{\mathrm{b}} .
$$

where $\rho_{\mathrm{b}}$ is the distance from the center of the grain face. The boundary conditions for Equation (65) are $C_{b}\left(\dot{\rho}_{\mathrm{b}}=\mathrm{R}_{\mathrm{b}}\right)=0$ and

$$
\left.\frac{\partial C_{b}}{\partial \rho_{b}}\right|_{\rho b=0}=0 \text {. }
$$

As before, $D_{b}$ should not exceed $D_{g}$.

Under certain conditions the gas concentration on the boundaries can build up to the point where the bubbles can form a connected path to the grain edge. It is assumed that when this occurs gas is drained completely out of the grain boundary to the edge and the boundary heals. Gas can then build up agaln in the boundary and when interconnectivily recurs, the gas is again transterred to the edge, elc. Ouce $\dot{a}_{b}$ becomes large enough that interconnection becomes frequent, then it is desirable to obtain the average swelling under those conditions.

The fraction of the grain boundary covered by bubbles is given by $\pi r_{h}^{2} N_{h}^{\prime}$. Transfer to the grain edge is assumed to occur when this fraction is equal to approximately 0.78 (Reference 3 ). For simplicity, it is assumed that transfer to the boundary edge through grain boundary gas bubble interconnectivity results in complete depletion of gas at the boundary. Define $t$ as the time necessary to build the gas concentration from zero back up to a concentration necessary for interconnect transfer to the edge and $t$ is the time in this interval since the last complete transfer to the edge. The number of gas atoms per unit area on the boundary will be given by

$$
\mathrm{m}_{\mathrm{b}}=\dot{\mathrm{a}}_{\mathrm{b}} \mathrm{t} \lambda / \Omega
$$

From Reference 7, the number of gas atoms in the average grain boundary bubble as a function of time since the last transfer to the edge is given by substituting Equation (66) into Equation (62):

$$
\mathrm{n}_{\mathrm{b}}=2.39\left[\AA\left(\frac{\dot{\mathrm{a}}_{\mathrm{b}} \mathrm{t} \lambda}{\Omega}\right)^{1.12} \frac{\tau}{\delta_{\mathrm{b}}^{2.76}}\right]^{0.49} .
$$

In Equation (67) the smaller second term of Equation (62) has been dropped. Under conditions where small grain boundary bubble interconnectivity is expected, the second term is much smaller than the first. For example, at $1000^{\circ} \mathrm{C}$ and at a fission rate of $10^{13}$ fissions $/ \mathrm{cm}^{3}$ second, and for a grain radius of $l \mu$, the first term of Equation (62) has a value of 25 and the second has a value of 2.6; so dropping the second term is reasonable. The number of grain boundary gas bubbles per unit area of boundary as a function of time is given in Reference 7 by

$$
\mathrm{N}_{\mathrm{b}}^{\prime}=\frac{\dot{\mathrm{a}}_{\mathrm{b}} \mathrm{t} \lambda}{\Omega \mathrm{n}_{\mathrm{b}}} .
$$

From Reference 7, transfer to the edges will occur when

$$
\pi \mathrm{r}_{\mathrm{b}}^{2} \mathrm{~N}_{\mathrm{b}}^{i}=0.78
$$

Substituting Equations (55) and (68) into Equation (69) gives (Reference 7)

$$
\frac{\dot{a}_{b} t \lambda \pi \delta_{b}^{2}}{\Omega_{n_{b}^{1 / 3}}}=0.78 .
$$

Per Reference 7, substituting Equation (67) into Equation (70) and solving for t gives the time between interconnection and transfer to the grain edges, $t$, as

$$
t_{\zeta}=\frac{0.261 \Omega}{\dot{a}_{b} \lambda} \frac{(\bar{A} \tau)^{0.2}}{\delta_{b}^{3}}
$$

From Reference 7, the average number of gas atoms in a grain boundary bubble is given by solving

$$
<n_{b}>=\frac{1}{t} \int_{0}^{t} n_{b} d t
$$

where $n_{b}$ is given by Equation (67). From Reference 7, the integral in Equation (72) reduces to

$$
<\mathrm{n}_{b}>=1.54\left[\frac{\mathrm{A}_{\tau}}{\delta_{b}^{2.76}}\right]^{0.49}\left(\frac{\dot{a}_{b} \lambda}{\Omega}\right)^{0.5488} \xi_{\mathrm{p}}^{0.5488}
$$


The average number of bubbles on the grain boundary per unit area (Reference 7) is

$$
<\mathrm{N}_{\mathrm{b}}>=\frac{\dot{\mathrm{a}}_{\mathrm{b}} \mathrm{t}_{\mathrm{r}} \lambda}{2 \Omega<\mathrm{n}_{\mathrm{b}}>}
$$

The total grain boundary swelling per unit volume is given by multiplying the grain boundary area per unit volume by the swelling per unit area. The grain boundary area per unit volume is equal to $3 /\left(2 R_{g}\right)$, where $R_{g}$ is the grain radius. The swelling per unit volume due to the grain boundary bubbles is given by

$$
\left.\frac{\Delta \mathrm{V}}{\mathrm{V}}\right|_{\mathrm{b}}=\frac{3}{2 \mathrm{R}_{\mathrm{g}}} \alpha \mathrm{r}_{\mathrm{b}}^{3}<\mathrm{N}_{\mathrm{b}}>
$$

The average gas concentration on the grain boundary is given by

$$
<\mathrm{C}_{\mathrm{b}}>=<\mathrm{n}_{\mathrm{b}}><\mathrm{N}_{\mathrm{b}}>\frac{\Omega}{\lambda} .
$$

\section{Grain Boundary Gas Bubble Swelling and Gas Migra- tion for Bubble Radius $>25 \AA$}

The previous section assumes complete grain boundary bubble destruction; however, quite early, even at relatively low temperatures, grain boundary bubbles become too large to be destroyed by a single encounter with a fission fragment.

As in the case of the large intragranular bubbles, the ideal gas law is assumed to hold for the large grain boundary bubbles when the number of atoms in a bubble is calculated. As before, gas is knocked out of the grain boundary bubbles at the rate

$$
\frac{\mathrm{n}_{\mathrm{b}}}{\tau} \text {. }
$$

As stated in Reference 7, isolated grain boundary gas atoms migrate to the grain boundary bubbles at the rate

$$
\frac{2 \pi \mathrm{D}_{\mathrm{g}} \mathrm{C}_{\mathrm{Ib}} \lambda}{\ln \left(\mathrm{R}^{\prime} / \mathrm{r}_{\mathrm{b}}\right) \Omega}
$$

where $C_{\mathrm{Ib}}$ is the concentration of isolated grain boundary gas atoms and $\mathrm{R}^{\prime}$ is half the distance between grain boundary bubbles. In steady state the rates given by Equations (77) and (78) are equal, and therefore, from Reference 7 ,

$$
\mathrm{C}_{\mathrm{Ib}}=\frac{\mathrm{n}_{\mathrm{b}} \Omega}{2 \pi \tau \mathrm{D}_{\mathrm{g}} \lambda} \ln \left(\frac{\mathrm{R}^{\prime}}{\mathrm{r}_{\mathrm{b}}}\right)
$$

The large gas bubbles obey the ideal gas law to close approximation; therefore, the bubble radius is given by

$$
\mathrm{r}_{\mathrm{b}}=\left(\frac{\mathrm{kT} \mathrm{n}_{\mathrm{b}}}{2 \gamma \alpha \sin \varphi}\right)^{1 / 2}=\mathrm{B}_{\mathrm{b}} \mathrm{n}_{\mathrm{b}}^{1 / 2} .
$$

The grain boundary bubbles can also grow by coalescence. As stated in Reference 3, the lifetime of a bubble containing $n_{b}$ atoms is

$$
t_{\mathrm{n}_{\mathrm{b}}}=\frac{\mathrm{n}_{\mathrm{b}}^{1.12} \mathrm{r}_{\mathrm{b}}^{2.76}}{9.45 \AA\left(\mathrm{N}_{\mathrm{b}}^{\prime} \mathrm{n}_{\mathrm{b}}\right)^{1.12}},
$$

where $\mathbf{N}_{\mathrm{h}}^{\prime}$ is the number of gas bubbles per unit area. From Reference 7, substituting Equation.(80) into (81) gives

$$
t_{b}=\frac{B_{b}^{2.76} n_{b}^{1.38}}{9.45 A N_{b}^{\prime 1.12}}
$$

Since

$$
\frac{\mathrm{dn}}{\mathrm{d} t}=\frac{2 \mathrm{n}_{\mathrm{b}}-\mathrm{n}_{\mathrm{b}}}{\mathrm{t}_{\mathrm{n}_{\mathrm{b}}}},
$$

then due to coalescence (Reference 7),

$$
\frac{\mathrm{dn}_{\mathrm{b}}}{\mathrm{dt}}=\frac{9.45 \AA \mathrm{N}_{\mathrm{b}}^{\prime 1.12}}{\mathrm{~B}_{\mathrm{b}}^{2.76} \mathrm{n}_{\mathrm{b}}^{0.38}} .
$$

According to Reference 7, the total rate of change of the gas in a bubble can be written

$$
\frac{\mathrm{dn}_{\mathrm{b}}}{\mathrm{dt}}=\frac{9.45 \AA \mathrm{N}_{\mathrm{b}}^{1.12}}{\mathrm{~B}_{\mathrm{b}}^{2.76} \mathrm{n}_{\mathrm{b}}^{0.38}}+\frac{2 \pi \mathrm{D}_{\mathrm{g}} \mathrm{C}_{\mathrm{Ib}} \lambda}{\ln \left(\mathrm{R}^{\prime} / \mathrm{r}_{\mathrm{b}}\right) \Omega}-\frac{\mathrm{n}_{\mathrm{b}}}{\tau} .
$$

From the steady-state conditions of Equation (79), the last two terms of Equation (85) cancel and from cunservation of matter

$$
\mathbf{N}_{\mathrm{b}}^{\prime}=\frac{\lambda}{\Omega \mathrm{n}_{\mathrm{b}}}\left(\mathrm{C}_{\mathrm{b}}-\mathrm{C}_{\mathrm{Ib}}\right)
$$

For small bubbles $C_{b}>>C_{I b}$, s.o the $C_{I b}$ term of Equation (86) will be dropped. For $\mathrm{UO}_{2}$ fissioning at $10^{13}$ fissions $/ \mathrm{cm}^{3}$ second at $1000^{\circ} \mathrm{C}$ and for a grain radius of $l \mu$, we have $C_{b}=0.35$ and $C_{I b}$ $=0.01$; therefore, the approximation is reasonable. Equation (85) now, per Reference 7, becomes

$$
\frac{d n_{b}}{d t}=\frac{9.45 A}{B_{b}^{2.76} n_{b}^{3 / 2}}\left(\frac{\lambda C_{b}}{\Omega}\right)^{1.12}
$$


Equation (87) can be integrated (Reference 7) to give

$$
n_{\mathrm{b}_{2}}=\left[\frac{23.6 \mathrm{~A}}{\mathrm{~B}_{\mathrm{b}}^{2.76}}\left(\frac{\lambda}{\Omega}\right)^{1.12} \mathrm{C}_{\mathrm{b}}^{1.12} \Delta \mathrm{t}+\mathrm{n}_{\mathrm{b}_{1}}^{5 / 2}\right]^{2 / 5},
$$

where $n_{b 2}$ is the number of atoms in a bubble, initially containing $n_{b_{1}}$ atoms, after a time $\Delta t$. Using $\mathrm{r}_{\mathrm{b}}$ calculated from Equation (88), the bubble radius can be obtained, and hence the bubble diffusion coefficient. Knowing the bubble diffusion coefficient, Equation (65) can be solved and gas migration to the grain edges can be predicted. The grain boundary bubble radius is

$$
\mathrm{P}_{\mathrm{crr}}{ }^{4}+2 \gamma\left(\mathrm{rr} \mathrm{r}^{3}-(\operatorname{Pn} \beta-\mathrm{nkT})_{\mathrm{r}}-2 \gamma \mathrm{n} \beta=0 .\right.
$$

Equation (89) is then solved in exactly the same fáshion as Equation (47a).

Equation (88) is valid only as long as the gas bubbles on the boundary cannot form an interconnected path to the grain edge; in the low temperature case that may happen very snon. Once $\dot{a}_{h}$ becoines larye enough that interconnection becomes frequent, it is then desirable to obtain the average swelling under those conditions as before.

As reported in Reference 3, the gas on the boundaries is transferred to the grain edges when $\pi \mathrm{B}_{b}^{2} \lambda \mathrm{C}_{\mathrm{b}} / \Omega=0.78$. From Reference 7 , this gives $\mathrm{C}_{\mathrm{b}}$ upon transfer as

$$
C_{b}=\frac{0.78 \Omega}{\pi B_{b}^{2} \lambda} .
$$

Gas arrives at the boundary at the rate $\dot{a}_{b}$ so that the time it takes to transfer the gas from boundary to edge (Reference 7) is

$$
\mathrm{t}_{\mathrm{r}}=\frac{0.78 \Omega}{\pi \mathrm{B}_{\mathrm{b}}^{2} \lambda \dot{\mathrm{a}}_{\mathrm{b}}}
$$

The average number of gas atoms in a grain boundary bubble is given by solving Equation (72), where $n_{b}$ is given by solving a modified Equation (87) (Reterence 7):

$$
\frac{d n_{b}}{d t}=\frac{9.45 \AA}{B_{b}^{2.76} n_{b}^{3 / 2}}\left(\frac{\lambda \ddot{a_{b}}}{\Omega}\right)^{1.12} t^{1.12} .
$$

To obtain $n_{b}(t)$, Equation (92) is integrated (Reference 7):

$$
\int_{0}^{n_{b}} n_{b}^{3 / 2} d_{n_{b}}=\int_{0}^{t} \frac{9.45 A}{B_{b}^{2.76}}\left(\frac{\lambda \dot{a}_{b}}{\Omega}\right)^{1.12} t^{1.12} d t .
$$

From Reference 7, upon solution,

$$
\mathbf{n}_{b}=\left[11.1 \frac{\AA}{B_{b}^{2.76}}\left(\frac{\lambda \dot{a}_{b}}{\Omega}\right)^{1.12} \mathrm{t}^{2.12}\right]^{2 / 5} .
$$

Substituting Equation (94) into Equation (72), $\left\langle n_{b}\right\rangle$ is obtained (Reference 7 ):

$$
<\mathrm{n}_{\mathrm{b}}>=\left[\frac{2.39 \AA}{\mathrm{B}_{\mathrm{b}}^{2.76}}\left(\frac{\lambda \dot{\mathrm{a}}_{\mathrm{b}}}{\Omega}\right)^{1.12} \mathrm{t}_{\mathrm{c}}^{2.12}\right]^{2 / 5}
$$

From Reference 7, substituting Equation (91) into Equation (95) gives

$$
<\mathrm{n}_{\mathrm{b}}>=\left[\frac{1.41 \mathrm{~A} \Omega}{\dot{\mathrm{a}}_{\mathrm{b}} \pi^{2.12} \mathrm{~B}_{\mathrm{b}}^{\prime} \lambda}\right]^{2 / 5} .
$$

'The average number of bubbles per unit area of boundary is given by Equation (74), which is equal in (Reference 7)

$$
<\mathrm{N}_{\mathrm{b}}>=\frac{0.78}{2 \pi \mathrm{B}_{\mathrm{b}}^{2}<\mathrm{n}_{\mathrm{b}}>} .
$$

Knowing the bubble radius and the number of bubbles per unit area of boundary given by Equation (97), the swelling due to grain boundary bubbles can be calculated.

The average gas concentration on the grain boundary is given by

$$
\begin{aligned}
<\mathrm{C}_{\mathrm{b}}> & =<\mathrm{n}_{\mathrm{b}}><\mathrm{N}_{\mathrm{b}}>\frac{\Omega}{\lambda} \\
& =\frac{0.78 \Omega}{2_{0} \mathrm{~B}_{\mathrm{b}}^{2} \lambda} .
\end{aligned}
$$

The discussion of grain boundary gas atom behavior is complete. A discussion of grain boundary edge behavior follows.

\section{E. Grain Edge Gas Bubble Swelling and Gas Migration}

As in the case of intragranular bubbles and grain boundary bubbles, the gas bubbles on the grain edges can be destroyed by fission fragments if they are smaller than approximately $25 \AA$ radius. The dispersed gas atoms are knocked on the average about $15 \AA$ from the grain boundary and can, therefore, easily migrate back to the boundary before being trapped by other sinks. The fact that the gas bubble was originally at a boundary edge 
means that when the gas atoms migrate back to the boundary they will be very close to the edge (approximately $15 \AA$ ) and hence will migrate in the boundary to the edge before being captured at other traps in the boundary. Therefore, the grain edge can be treated as a perfect trap. Once back on the edge, the gas migrates nucleating new gas bubbles which in turn migrate and coalesce with one another. The gas bubbles continue to grow by coalescence until destroyed by another fission fragment.

In order to calculate grain edge bubble growth, it is necessary to develop a technique similar to that used for the intragranular bubbles and the grain boundary bubbles. The isolated gas atoms formed by the destruction of a gas bubble migrate until they collide with one another forming twoatom bubbles. The two-atom bubbles migrate until they collide, forming four-atom bubbles, etc. As in the two- and three-dimensional cases, assume a "bubble lattice" on the grain edge with lattice parameter $2 r_{e}$. where $r_{e}$ is the radius of a grain boundary edge bubble. The concentration, $\mathrm{C}_{\mathrm{e}}^{\prime}$, of gas bubbles is the fraction of sites occupied by bubbles. If $S_{n}$ is the number of new sites visited by a bubble after $n_{e}^{\prime}$ jumps, then the number of jumps to coalescence, $\overline{\mathrm{n}}_{\mathbf{e}^{\prime}}^{\prime}$ is calculated by solving

$$
1=\int_{0}^{\bar{n}_{e}^{\prime}} \frac{\partial S_{n}}{\partial n_{e}^{\prime}} C_{e}^{\prime} d n_{e}^{\prime}
$$

For random walk confined to a line, Vineyard (Reference 9) found

$$
S_{u}=\left(\frac{8 n_{e}^{\prime}}{\pi}\right)^{1 / 2}
$$

Substituting Equation (101) into Equation (100) and solving for $\overline{\mathrm{n}}_{\mathrm{e}}^{\prime}$ yields

$$
\bar{n}_{\mathbf{e}}^{\prime}=\frac{\pi}{8 C_{e}^{\prime}}
$$

as the number of jumps a grain edge bubble must make to coalesce with another gas bubble of the same size. Defining $\mathrm{N}_{\mathrm{e}}$ as the number of gas bubbles per unit length, $\overline{\mathbf{n}}_{e}^{\prime}$, is given by

$$
\overline{\mathrm{n}}_{\mathrm{e}}^{\prime}=\frac{\pi}{8 \mathrm{~N}_{\mathrm{a}}^{2} 4 \mathrm{r}_{\mathrm{e}}^{2}} .
$$

The relative jump frequency between two bubbles confined to motion on a line is

$$
\Gamma=\frac{D_{b}}{r_{e}^{2}}
$$

where $D_{b}$ is the bubble diffusion coefficient. From Reference 7 , the time for a bubble containing $\dot{n}_{e}$ atoms to coalesce is

$$
t_{\mathrm{n}_{e}}=\frac{\overrightarrow{\mathrm{n}}_{\mathrm{e}}^{\prime}}{\Gamma}=\frac{\pi}{32 \mathrm{~N}_{\mathrm{e}}^{2} \mathrm{D}_{\mathrm{b}}^{\prime}}
$$

The number of gas atoms on the grain edge per unit length, $\mathrm{m}_{e}$, is given by

$$
\mathrm{m}_{\mathrm{e}}=\mathrm{N}_{\mathrm{e}} \mathrm{n}_{\mathrm{e}} \text {. }
$$

Using this and Equation (11), Equation (105) can be written as

$$
t_{n_{\theta}}=\frac{\pi n_{e}^{2} r_{e}^{3}}{32 m_{e}^{2} A} .
$$

For small bubbles the gas obeys van der Waals gas law and the bubble radius is given by Equation (4), which can be written

$$
r_{e}=\delta n_{e}^{1 / 3}+\xi n_{e}^{2 / 3} .
$$

For bubbles smaller than approximately $25 \AA$, the second term on the right-hand side of Equation (108) is much smaller than the first; therefore, $r_{e}^{3}$ can be written

$$
r_{e}^{3}=\delta^{3} n_{e}+3 \delta^{2} \xi n_{e}^{4 / 3} .
$$

Substituting Equation (109) into Equation (107) yields

$$
t_{\mathrm{n}_{e}}=\frac{\pi \delta^{2}}{32 \dot{m}_{\mathrm{e}}^{2} \AA}\left(\delta \mathrm{n}_{\mathrm{e}}^{3}+3 \xi \mathrm{n}_{\mathrm{e}}^{10 / 3}\right) .
$$

The time between fission fragment damage events, $\tau$, is given by

$$
\tau=t_{1}+t_{2}+t_{4}+t_{8}+\ldots t_{\underline{n}_{e}},
$$

where $n_{0}$ is the number of atoms in a bubble at destruction. Equation (111) can be written as

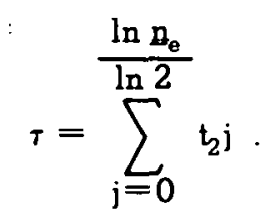

The summation given by Equation(112) can be written as an integral if $j$ is large. Substituting Equation (110) into the integral form yields

$$
\tau=\frac{\pi \delta^{2}}{32 \mathrm{~m}_{\theta}^{2} A} \int_{0}^{\frac{\ln \underline{n}_{\theta}}{\ln 2}}\left(\delta 2^{3 j}+3 \xi 2^{(10 / 3) j}\right) d j
$$


Equation (113) yields

$$
\tau=\frac{\pi \delta^{2}}{32 \mathrm{~m}_{\mathrm{e}}^{2} \mathrm{~A}}\left[\frac{\delta \underline{\mathrm{n}}_{\mathrm{e}}^{3}}{3 \ln 2}+\frac{9}{10} \cdot \frac{\xi}{\ln 2} \underline{\mathrm{n}}_{\mathrm{e}}^{10 / 3}\right] .
$$

From Reference 7, solving Equation (114) for $\mathrm{n}_{e}$ yields

$$
\mathrm{n}_{\mathrm{e}} \equiv\left(\frac{21.2 \mathrm{~m}_{\mathrm{e}}^{2} \mathrm{~A} \tau}{\delta^{3}}\right)^{3 / 9}-0.899 \frac{\xi}{\delta}\left(\frac{21.2 \mathrm{~m}_{\mathrm{e}}^{2} \tau \mathrm{A}}{\delta^{3} .}\right)^{4 / 9}
$$

The average value of $n_{e}$, the average number of atoms in a bubble during the time interval $\tau$, is

$$
\left\langle\mathrm{n}_{\mathrm{e}}\right\rangle=\frac{1}{\tau} \int_{0}^{T} \underline{\mathrm{n}}_{\theta}(\mathrm{t}) \mathrm{dt} .
$$

$\underline{n}_{e}(t)$ is given by substituting $t$ for $\tau$ in Equalivu (110). From Reterence 1, the solution of Equation $(116)$ is

$$
\begin{aligned}
<\mathrm{n}_{\mathrm{e}}>= & 2.08\left(\frac{\mathrm{m}_{\mathrm{e}}^{2} \AA \tau}{\delta^{3}}\right)^{3 / 9} \\
& -2.42 \frac{\xi}{\delta}\left(\frac{\mathrm{m}_{\mathrm{e}}^{2} \tau \AA}{\delta^{3}}\right)^{4 / 9} .
\end{aligned}
$$

The average bubble radius, $\left\langle r_{e}\right\rangle$, is given by substituting $\left\langle\mathrm{n}_{e}\right\rangle$ into Equation (4). The longrange diffusion coefficient of the gas is given by substituting $\left\langle r_{\theta}\right\rangle$ into Equation (11).

The gas can migrate along the grain edges to the grain corners where it is trapped. The gas migration is described by the transport equation in one dimension given by

$$
\frac{\partial C_{e}}{\partial t}=\frac{\partial}{\partial X} D \frac{\partial C_{e}}{\partial X}+\dot{a}_{e}
$$

where $\dot{a}_{e}$ is the rate that gas arrives at the grain edge from the boundary and is given by

$$
\begin{array}{r}
\dot{a}_{\theta}=\left(\dot{a} N_{o} \Delta t-\Delta C N_{o}\right. \\
\left.-\frac{3 \Delta C_{b}}{2 R_{g} \lambda^{2}}\right) \frac{n_{g} \Pi_{b} \lambda}{\Delta t}
\end{array}
$$

where $\Delta C$ is the change in the average gas concentration in the grain interior in units of atom fraction in time $\Delta t$, and $\Delta C_{b}$ is the change in the gas concentration on the grain boundary in units of the fraction of boundary site occupied in time $\Delta t$. The average gas concentration on the grain boundaries is given by

$$
<\mathrm{C}_{\mathrm{b}}>=\frac{1}{\pi \mathrm{R}_{\mathrm{b}}^{2}} \int_{0}^{\mathrm{R}_{\mathrm{b}}} \mathrm{C}_{\mathrm{b}}\left(\rho_{\mathrm{b}}\right) 2 \pi \rho_{\mathrm{b}} \mathrm{d} \rho_{\mathrm{b}}
$$

where $\mathrm{C}\left(\rho_{\mathrm{b}}\right)$ is calculated from Equation (65). $\left\langle\mathrm{C}_{\mathrm{b}}\right\rangle$ may also be obtained from Equation (76) or from Equation (98), whichever is applicable.

Equation (118) is solved by a finite difference scheme similar to that for the grain interior and grain boundary cases. The edge length, $\mathrm{E}_{\ell}\left(=0.719 \mathrm{R}_{\mathrm{g}}\right)$, is the distance along the edge between grain corners. The boundary conditions for Equation (118) are $\partial \mathrm{C}_{e} / \partial \mathrm{X}=0$ at $\mathrm{X}=0$, and $\mathrm{C}_{e}$ $=0$ at $X= \pm E_{\ell} / 2$. The grain edge swelling is given by

$$
\left.\frac{\Delta V}{V}\right|_{\theta}=\frac{4 m\left\langle r_{e}\right\rangle^{3}\left\langle C_{\theta}\right\rangle}{\left.3<n_{\theta}\right\rangle R_{g} R_{b} \lambda}
$$

where $\left\langle\mathrm{C}_{u}\right\rangle$ is the average concentration on the edge.

Before the edge bubbles become very large, interconnection of the bubbles takes place and the gas is transported to the grain corners. This happens when $C_{e}$ is approximately equal to one. The edge gas concentration then goes to zero. Gas, then, begins to accumulate again at the grain edges as before. Defining $t$ as the time since the last interconnection event and $t$ as the time between intercunnection events, the edge gas concentration is given by

$$
\mathrm{C}_{\theta}=\dot{\mathrm{a}}_{\mathrm{e}} \mathrm{t}
$$

or, in terms of the number of gas atoms per unit length, $\mathrm{m}_{\mathrm{a}} i$ as

$$
m_{e}=\frac{d_{e} t}{\lambda}
$$

Also,

$$
t=\frac{1}{d_{e}}
$$

Substituting $m_{0}$ from Equation (121) into Equation (117) for $\left\langle\mathrm{n}_{\mathrm{e}}\right\rangle$ and dropping the smaller second term of Equation (117) yields

$$
\mathrm{n}_{\mathrm{e}}=2.08\left(\frac{\dot{\mathrm{a}}_{\mathrm{e}}^{2} \mathrm{t}^{2} \mathrm{~A} \tau}{\lambda^{2} \delta^{3}}\right)^{1 / 3}
$$


The average number of atoms in a grain edge bubble is given by

$$
<n_{e}>=\frac{1}{t} \int_{0}^{t} n_{e} d t .
$$

Substituting Equation (123) into Equation (124) and integrating (Reference 7 ) yields

$$
<\mathrm{n}_{\mathrm{e}}>=1.25 \frac{(\overline{\mathrm{A}} \tau)^{1 / 3}}{\lambda^{2 / 3} \delta}
$$

as the average number of gas atoms in a grain edge bubble once interconnectivity of edge bubbles takes place. From Reference 7, the average number of bubbles on the grain edge per unit length, $\left\langle N_{e}\right\rangle$, is given by

$$
<\mathrm{N}_{\mathrm{e}}>=\frac{\dot{\mathrm{a}}_{\mathrm{e}} \mathrm{t}_{\mathrm{r}}}{2 \lambda<\mathrm{n}_{\mathrm{e}}>}=\frac{\delta}{2.5 \lambda^{1 / 3}(\mathrm{~A} \tau)^{1 / 3}}
$$

From Equations (125) and (126), the grain edge swelling and gas concentrations can be calculated. The average gas concentration on the edge is given by

$$
\left\langle\mathrm{C}_{\mathrm{e}}\right\rangle=\frac{2}{\mathrm{E}_{\ell}} \int_{0}^{\mathrm{E}_{\ell / 2}} \mathrm{C}_{\theta}(\mathrm{x}) \mathrm{d} \mathrm{x} .
$$

where $\mathrm{C}_{e}(x)$ is obtained from Equation (118) or if interconnection is taking place, then $\left\langle\mathrm{C}_{e}\right\rangle$ $=0.5$.

The average bubble radius is given by substituting $\left\langle\mathrm{n}_{\mathrm{e}}\right\rangle$ from Equation (125) into Equation (47a) and solving Equation (47a) for $r$.

The number of gas atoms per $\mathrm{cm}^{3}$ in the matrix is given by

$$
<\mathrm{m}>=<\mathrm{C}>\mathrm{N}_{\mathrm{o}} .
$$

The number of gas atoms per $\mathrm{cm}^{3}$ on the grain boundaries is given by

$$
<\mathrm{m}_{\mathrm{b}}>=<\mathrm{C}_{\mathrm{b}}>\frac{3}{2 \mathrm{R}_{\mathrm{g}} \lambda^{2}} .
$$

The number of gas atoms per $\mathrm{cm}^{3}$ on grain boundary edges is given by

$$
<\mathrm{m}_{\mathrm{e}}>=\frac{\left\langle\mathrm{C}_{\mathrm{e}}\right\rangle}{\mathrm{R}_{\mathrm{g}} \mathrm{R}_{\mathrm{b}} \lambda} .
$$

The total number of gas atoms in the grain corners per $\mathrm{cm}^{3}$ is given by

$$
\begin{aligned}
<\mathrm{m}_{\mathrm{c}}>= & \int_{0}^{\mathrm{t}}(0.3 \text { or } 0.34) \dot{\mathrm{i}}\left(\mathrm{t}^{\prime}\right) \mathrm{dt} \\
& -<\mathrm{m}>-<\mathrm{m}_{\mathrm{b}}>-<\mathrm{m}_{\mathrm{e}}>,
\end{aligned}
$$

where the integral is the total number of gas atoms generated either from ${ }^{235} \mathrm{U}$ or ${ }^{233} \mathrm{U}$. The number of corners per unit volume is equal to $0.695 /\left(R_{g}^{2} R_{b}\right)$; therefore, the number of gas atoms in a corner bubble, $n_{c^{\prime}}^{\prime}$ is given by

$$
\mathrm{n}_{\mathrm{c}}^{\prime}=<\mathrm{m}_{\mathrm{c}}>\mathrm{R}_{\mathrm{g}}^{2} \mathrm{R}_{\mathrm{b}} / 0.695 .
$$

The $\mathbf{n}_{c}^{\prime}$ from Equation (132) can be substituted into Equation (47a) to calculate the corner bubble radius, $r_{c}$. The swelling due to the corner bubbles is given by

$$
\left.\frac{\Delta V}{V}\right|_{c,}=\frac{4}{3} \pi r_{c}^{3} \frac{0.695}{R_{g}^{2} R_{b}}
$$

if there is no grain boundary porosity.

The total swelling is given by

$$
\frac{\Delta V}{V}=\left.\frac{\Delta V}{V}\right|_{m}+\left.\frac{\Delta V}{V}\right|_{b}+\left.\frac{\Delta V}{V}\right|_{e}+\left.\frac{\Delta V}{V}\right|_{c} .
$$

\section{F. Tunnel Formation}

At low temperatures the gas is confined primarily to the grain interiors. At higher temperatures the gas migrates to the boundaries, edges, and corners where the bubbles can become very large. It has been observed that tunnels form along the grain boundary edges when the swelling of corner and edge bubbles exceeds 5 percent. It is further assumed that gas that migrates to the tunnels escapes from the fuel and is released.

The tunnels once formed have a tendency to heal by sintering. The tunnels can grow if the number of vacancies brought to them by the gas bubbles from the grain boundaries exceeds the vacancies migrating out of the tunnels due to sintering. Turnbull and Tucker (Reference 10) have considered tunnel formation and sintering in detail. They found that the sintering flux or the flux of vacancies out of the tunnel surrounding one grain face is given by (Reference 10)

$$
J=\frac{12 \pi \gamma \delta^{\prime} D_{g b}\left(b^{-1}+R_{b}^{-1}\right)}{k T\left(1+\frac{b D_{g b}}{2 R_{b} D_{s}}\right)}
$$


where

$$
\begin{aligned}
& D_{g b}= \text { self-diffusion coefficient within a dis- } \\
& \text { tance } \delta^{\prime} \text { of the grain boundary } \\
& b=\text { tunnel radius } \\
& R_{b}= \text { grain face radius given by Equation (64) } \\
& D_{s}=\text { surface self-diffusion coefficient. }
\end{aligned}
$$

The total vacancy flux out of the tunnels per unit volume is given by

$$
\mathrm{J}_{\mathrm{s}}=\frac{\mathrm{J}}{2 \pi \mathrm{R}_{\mathrm{g}} \mathrm{R}_{\mathrm{b}}^{2}},
$$

where $R_{\mathrm{g}}$ is the grain radius.

The total number of gas atoms going out of the boundary into the edge tunnels per unit volume per unit time is

$$
\frac{\dot{\mathrm{a}}_{\dot{\mathrm{s}}}}{\lambda \mathrm{R}_{\mathrm{g}}} \cdot
$$

where $\dot{a}_{e}$ is the gas atom production rate in atom fraction per unit length of edge. The total number of gas bubbles per unit volume per unit time going from the boundary to the edge tunnels is given by

$$
\frac{\dot{a}_{e}}{\lambda R_{g} R_{b}<n_{b}>1}
$$

where $\left\langle\mathrm{n}_{\mathrm{b}}\right\rangle$ is the average number of gas atoms in a grain boundary bubble given by Equation (62), (73), (88), or (96) depending on the operating conditions. The bubble radius is given by substituting the appropriate value of $\left\langle n_{b}\right\rangle$ into either Equation (55) or (80). The total number of vacancies arriving at the tunnels per unit time and volume is given by multiplying the number of bubbles arriving, Equation (138), by $\alpha<r_{b}>3$, where $\alpha$ is given by Equation (51), and dividing by the atomic volume, $\Omega$. The number of vacancies arriving per unit volume and unit time is qiven by

$$
J_{a}=\frac{\dot{u}_{e}}{\lambda R_{g} R_{h}<n_{h}>} \frac{a<b_{b}>?}{\Omega} .
$$

The swelling due to tunnel formation is therefore

$$
\left.\frac{\Delta V}{V}\right|_{T}=\left(J_{a}-J_{s}\right) \Omega
$$

If $J_{s}$ is greater than $J_{a}$, then the tunnel network shrinks to the 5-percent volume size. At 5-percent volume the tunnels pinch off and form gas-free pores at the grain corners, maintaining the 5percent volume. These pores heal just as the initial fabricated porosity healed, as discussed in Section II.K. In this work it will be assumed that once the tunnel network forms, it remains stable even if $\mathrm{J}_{\mathrm{s}}>\mathrm{J}_{\mathrm{a} i}$ the tunnels simply do not grow.

The total fraction of gas released, $f$, is given by

$$
A=\frac{\int_{0}^{1}(0.3 \text { or } 0.34) i\left(t^{\prime}\right) d t^{\prime}-\langle C\rangle N_{0}-\left\langle C_{b}\right\rangle \frac{3}{2 R_{g} \lambda^{2}}}{\int_{0}^{1}(0.3 \text { or } 0.34) i\left(t^{\prime}\right) d t^{\prime}}
$$

\section{G. Temperature Gradients}

In the case of the intragranular bubbles, spherical symmetry was used. In the presence of a temperature gradient the spherical symmetry is destroyed. In order to maintain the spherical symmetry, some ascumptions have to be made. As stated iil Reference 11, in the presence of a temperature gradient a gas bubble moves with a drift velocity given by

$$
\mathrm{v}=\frac{\mathrm{DF}}{\mathrm{kT}}
$$

where $F$ is the force on the bubble due to the temperature gradient and is given in Reference 11 by

$$
\mathrm{F}=\frac{4 \pi \mathrm{r}^{3} \mathrm{Q}^{*} \nabla \mathrm{T}}{3 \Omega \mathrm{T}}
$$

where $Q^{*}$ is the heat of transport and is a function of the transport function of the bubble, and $\nabla \mathrm{T}$ is the temperature gradient. If a bubble is placed in the center of a grain, then it will miqrate out of the grain in time $t$, given by

$$
t=\frac{R_{\mathrm{o}}}{\mathrm{v}}
$$

where $R_{q}$ is the grain radins

If a bubble io placed in the ceuler of a grain in the alsyuse of a tompcrature gradieul, llie lime it takes to migrate out is given by

$$
t=\frac{R_{g}^{2}}{6 D}
$$

From Reference 7, an effective diffusion coefficient is defined by equating Equations (144) and (145) to obtain

$$
D_{\text {eff }}=\frac{R_{g} v}{6}=\frac{R_{g} D F}{6 k T} .
$$

The diffusion coefficient used in Equation (22) is the sum of $D$ and $D_{\text {eff }}$. If the temperature gradient is 
zero, then $\mathrm{D}_{\text {eff }}$ is zero and normal diffusion holds. If $D_{\text {eff }}>>$ D, then Equation (146) moves the gas out of the grains in approximately the same time as Equation (144) would predict.

The effect of temperature gradients on grain boundary bubbles has not been considered. Section II.H shows that the swelling due to grain boundary bubbles and the gas collected by the grain boundary bubbles is typically very small and hence relatively unimportant. Including the effect of a temperature gradient would reduce the gas on the grain boundaries even more; thus, the effect of the temperature gradient on the grain boundary gas is negligible.

\section{H. Intragranular Densification}

This section deals with the densification of fabricated pores which are found in the fuel at the beginning of the reactor operation.

When a uranium atom fissions, two highly energetic fission fragments are produced. These fission fragments lose energy first by ionizing the lattice atoms and then by knocking the lattice atoms out of the lattice sites. The regions of displaced atoms, or damage cascades, consist of vacancy clusters surrounded by isolated interstitials and a few isolated vacancies. At the relatively high temperatures of interest, microannealing takes place and the vacancy clusters can agglomerate and collapse into vacancy dislocation loops. It will be assumed here that one loop. is formed for each fission fragment path. The cluster configuration has a very small effect on the point defect behavior because of the low density of the clusters. A large fraction of the interstitials migrate back to the damage cascade from which they originated. It will be assumed here that 10 percent of the interstitials created escape the damage cascade and become free to $\mathrm{mi}-$ grate through the lattice. In the swelling model, it is assumed that $1.0 \times 10^{5}$ lattice atoms are displaced per fission event. The number of interstitials assumed to escape the damage cascade is $10^{4}$. In Reference 12, the nuimber of vacanoies escaping the two damage cascades per fission event is given by

$$
\xi^{\prime}=10^{4}-2 \frac{\pi r_{d}^{2} b^{\prime}}{\Omega}
$$

where

$$
\begin{aligned}
& \overline{\mathrm{r}}_{\mathrm{d}}=\text { radius of the collapsed vacancy loop } \\
& \mathrm{b}^{\prime}=\text { Burgers vector of the loop } \\
& \Omega=\text { atomic volume. }
\end{aligned}
$$

The 2 in Equation (147) comes from the assumption that two damage cascades result from a fission event. In this work, the two cascades are treated as being of equal size.
The point defects, once created, can migrate to and be absorbed at dislocations, fabricated pores (henceforth called pores), damage cascades (treated as loops), grain or subgrain boundaries, and fission gas bubbles (neither treated as nor called pores). The point defects can also be destroyed by mutual recombination. The net absorption of interstitials at pores leads to densification, which is described by the MacEwen and Hastings (Reference 13) model. The calculation of the net arrival rate of interstitials to pores is the main concern here. Vacancy knockout by fission fragments will be discussed later.

From Reference 14, the loss rate of vacancies to dislocations is equal to

$$
\frac{2 \pi \rho^{\prime} D_{v}}{\ln \left(r_{l} / b^{\prime}\right)}\left(C_{v}-C_{o}\right)
$$

where

$$
\begin{aligned}
\rho^{\prime}= & \text { dislocation density } \\
\mathrm{D}_{\mathrm{v}}= & \text { vacancy diffusion coefficient } \\
\mathrm{C}_{\mathrm{v}}= & \text { average vacancy concentra- } \\
& \text { tion far from the dislocation } \\
\mathrm{C}_{0}= & \text { thermal equilibrium vacancy } \\
& \text { concentration } \\
\mathrm{r}_{1}\left(=1 / \sqrt{\pi \rho^{\prime}}\right)= & \text { half the distance between dis- } \\
& \text { locations. }
\end{aligned}
$$

The dislocation density as a function of temperature has been given by Warner and Nichols (Reference 15) as

$$
\begin{aligned}
\rho^{\prime}= & \exp \left(-2.07 \times 10^{-3}\left(\mathrm{~T}^{\prime}-273\right)\right. \\
& +21.82)
\end{aligned}
$$

where $\mathrm{T}$ is the absolute temperature and the dislocation density is in units of $\mathrm{cm}^{-2}$.

The loss rate of vacancies to pores is given in Reference 14 by

$4 \pi I_{p} N_{p} D_{v}\left\{C_{v}-C_{0} \exp \left[\frac{\Omega}{k T}\left(\frac{2 \gamma}{r_{p}}+P-P_{g}\right)\right]\right\}$.

where

$$
\begin{aligned}
\mathrm{r}_{\mathrm{p}}= & \text { pore radius (for simplicity only one pore } \\
& \text { size is considered) } \\
\mathrm{N}_{\mathrm{p}}= & \text { number of pores per unit volume } \\
\mathrm{k}= & \text { Boltzmann's constant } \\
\gamma= & \text { surface tension of the pore } \\
\mathrm{P}= & \text { externally applied hydrostatic pressure } \\
\mathrm{P}_{\mathrm{g}}= & \text { pressure due to any fission gas that has ac- } \\
& \text { cumulated in the pore. }
\end{aligned}
$$


The loss rate of vacancies to damage cascades is given in Reference 14 by

$$
\begin{aligned}
4 \pi^{2}{ }_{\mathrm{d}} N_{\mathrm{d}} D_{\mathrm{v}}\left\{C_{\mathrm{v}}-\mathrm{C}_{0}\right. \\
\left.\quad \exp \left[-\frac{\mu \mathrm{b} \Omega \ln \left(32 \mathrm{r}_{\mathrm{d}} / \mathrm{b}^{\prime}\right)}{4 \pi(1-\nu) \mathrm{r}_{\mathrm{d}} \mathrm{kT}}\right]\right\} / \ln \left(8 \mathrm{r}_{\mathrm{d}^{\prime}} / \mathrm{b}^{\prime}\right) .
\end{aligned}
$$

where

$$
\begin{aligned}
\mathbf{r}_{\mathrm{d}} & =\text { damage cascade radius } \\
\mathbf{N}_{\mathrm{d}} & =\text { number of cascades per unit volume } \\
\mu & =\text { shear modulus } \\
\nu & =\text { Poisson's constant. }
\end{aligned}
$$

From Reference 16, the loss rate of vacancies to grain or subgrain boundaries is given by

$$
\frac{3 k_{v} D_{v}}{R_{g}}\left(C_{v}-C_{o}\right)
$$

where $\bar{R}_{g}$ is the radius of the grain or subgrain and $k_{v}$ is given (Reference 16) by

$$
k_{v}=\left[\frac{2 \pi \rho^{\prime}}{\ln \left(r_{1} / b^{\prime}\right)}+4 \pi\left(r_{p} N_{p}+r_{d} N_{d}\right)\right]^{1 / 2} \text {. }
$$

The loss rate through recombination with interstitials is given in Reference 14 by

$$
\frac{5040\left(D_{i}+D_{v}\right)}{\lambda^{2}} C_{v} C_{i}
$$

where $C_{i}$ and $D_{i}$ are the interstitial concentration and diffusion coefficient, respectively, and $\lambda$ is the atomic jump distance.

The loss rate of vacancies to gas bubbles is difficult to calculate because the arrival of vacancies affects the energy of the gas. Hnwever, in pile densification of intragranular pores is usually finished by a depletion of $1-2 \times 10^{20}$ fissions $/ \mathrm{cm}^{3}$ and it is not necessary to calculate densification over a range of fission densities higher than this value. $\mathrm{Up}_{\mathrm{p}}$ to this depletion and at temperatures below ap= proximately $900^{\circ} \mathrm{C}$, fission gas remains as isolated gas atoms and is not in bubbles. Isolated gas atome would behave as any other impurity atom and would serve as trapping sites only and not as sink sites for puint defects. Large gas bubbles may serve as sink sites. An interstitial would still be necessary to annihilate a vacancy. It is assumed that recombination at a trap site is included in the term given by Equation (153). At temperatures above $900^{\circ} \mathrm{C}$, the vacancy concentration is approximately $\mathrm{C}_{n}$ so loss to large bubbles does not affect the vacancy concentration. Thus, the vacancy absorption at bubbles containing fission gas is not calculated (negligible effect) for this application.
By the use of Equations (148), (149), (150), (151), and (153), it can be shown that the rate of change in the vacancy concentration is given (Reference 12) by

$$
\begin{aligned}
& \frac{\mathrm{dC}_{\mathrm{v}}}{\mathrm{dt}}=\dot{\mathrm{f}} \Omega \xi-\frac{2 \pi \rho^{\prime} \mathrm{D}_{\mathrm{v}}}{\ln \left(\mathrm{r}_{1} / \mathrm{b}^{\prime}\right)}\left(\mathrm{C}_{\mathrm{v}}-\mathrm{C}_{\mathrm{o}}\right) \\
& +4 \pi r_{p} N_{p} D_{v}\left\{C_{o} \exp \left[\frac{\Omega}{k T}\left(\frac{2 \gamma}{r_{p}}+P-p_{g}\right)\right]\right. \\
& \left.-\mathrm{C}_{\mathrm{v}}\right\}+4 \pi^{2} \mathrm{r}_{\mathrm{d}} \mathrm{N}_{\mathrm{d}} \mathrm{D}_{\mathrm{v}}\left\{\mathrm{C}_{\mathrm{o}}\right. \\
& \left.\exp \left(+\frac{\mu b^{\prime} \Omega \ln \left(32 r_{d} / b^{\prime}\right)}{4 \pi(1-\nu) r_{d} k T}\right)-C_{v}\right\} / \ln \frac{8 r_{d}}{b^{\prime}} \\
& -\frac{5040\left(D_{i}+D_{v}\right)}{\lambda^{2}} C_{v} C_{i} \\
& -\frac{3 k_{v} D_{v}}{R_{g}}\left(C_{v}-C_{0}\right)
\end{aligned}
$$

where $\dot{f}$ is the fission rate.

An equation similar to Equation (154) exists for interstitials. It is given in Reference 12 by

$$
\begin{aligned}
\frac{d C_{i}}{d t}= & \dot{t} \Omega 10^{4}-\frac{2 \pi D_{i} C_{i} \rho^{\prime}}{\ln \left(r_{1} /\left(b^{\prime}+\Delta R\right)\right)} \\
& -4 \pi r_{p} N_{p} D_{i} C_{i}-4 \pi^{2} r_{d} N_{d} D_{i} C_{i} / \ln \left(\frac{8 r_{d}}{b^{\prime}}\right) \\
& -\frac{5040\left(D_{i}+D_{v}\right) C_{v} C_{i}}{\lambda^{2}} \\
& -\frac{3 k_{i} D_{i} C_{i}}{R_{g}}
\end{aligned}
$$

where from References 17 and 18,

$$
\Delta R=0.07 b^{\prime} \lambda^{3} \mu \epsilon / k T
$$

wher $\boldsymbol{t} t$ is the size mistit parameter of an interstitial in the lattice, and from Referenge 16

$$
\begin{aligned}
k_{i}= & {\left[\frac{2 \pi \rho^{\prime}}{\ln \left(r_{1} /\left(b^{\prime}+\Delta R\right)\right)}\right.} \\
& \left.+4 \pi\left(r_{p} N_{p}+r_{d} N_{d}\right)\right]^{1 / 2} .
\end{aligned}
$$

\section{Damage Cascades}

A simple and reasonable assumption, as was made in the case of depleted zones in Zircaloy in Reference 14, is that there is only one size of damage cascade. The size would be the average size of 
the cascade over its lifespan. The number of vacancies in such a cascade would be approximately . half the number there were when the cascade was created. If it is assumed that all of the vacancies are in the cascade cluster at creation (approximately $0.5 \times 10^{4}$ ), then the average cascade would have approximately half that number at midlife or approximately 2500 vacancies. The effective isolated vacancy generation rate would then be $\xi=5000$, and the cascade loop radius would be given by

$$
r_{d}=\left(\frac{2500 \Omega}{\pi b^{\prime}}\right)^{1 / 2}
$$

A cascade increases in size by absorbing vacancies. It decreases in size by absorbing interstitials and emitting vacancies. The net flux of interstitials to damage cascades per unit volume is given in Reference 12 by

$$
\begin{aligned}
J= & 4 \pi^{2} r_{d} N_{d} N_{o} / \ln \left(8 r_{d} / b^{\prime}\right)\left\{D_{i} C_{i}\right. \\
& +D_{v}\left[C_{o} \exp \left(-\frac{\mu b^{\prime} \Omega \ln \left(32 r_{d} / b^{\prime}\right)}{4 \pi(1-\nu) r_{d} k T}\right)\right. \\
& \left.\left.-C_{v}\right]\right\} .
\end{aligned}
$$

where $N_{0}$ is the number of lattice sites per unit volume.

The total net number of interstitials to fill all cascades is given by

$$
\frac{\pi r_{\mathrm{d}}^{2} \mathrm{~b}^{\prime} \mathrm{N}_{\mathrm{d}}}{\Omega}
$$

The rate (number per second) at which cascades are filled is Equation (160) divided by Equation (159). The change in the number of cascades due to filling is the number of cascades divided by the rate at which they are filled. The rate at which cascades are created is $2 \mathrm{t}$. From Reference 12 , the rate of change in the number of cascades is given by

$$
\begin{aligned}
\frac{d N_{d}}{d t}= & 2 \dot{f}-\frac{N_{d} 4 \pi}{r_{d} b^{\prime} \ln \left(8 r_{d} / b^{\prime}\right)}\left\{D_{i} C_{i}\right. \\
& +D_{v}\left[C_{o} \exp \left(-\frac{\mu b^{\prime} \Omega \ln \left(32 \dot{r}_{d} / b^{\prime}\right)}{4 \pi(1-\nu) r_{d} k T}\right)\right. \\
& \left.\left.-C_{v}\right]\right\} .
\end{aligned}
$$

\section{J. Pore Behavior}

Pores, as in the case ol dawage cascades, grow by absorbing vacancies; they shrink by absorbing interstitials and emitting vacancies. Letting $n_{p}$ be the number of interstitials it takes to fill a pore, then the net flux of interstitials to the pore is given (Reference 12) by

$$
\begin{aligned}
& \frac{d n_{p}}{d t}=4 \pi r_{p} N_{o} D_{i} C_{i}+4 \pi r_{p} N_{o} D_{v} \\
& \left\{C_{o} \exp \left[\frac{\Omega}{k T}\left(\frac{2 \gamma}{r_{p}}+P-P_{q}\right)\right]-C_{v}\right\} .
\end{aligned}
$$

The volume of a pore, $V_{p^{\prime}}$ is related to the pore radius and the number of interstitials to fill the pore by the equation

$$
\mathrm{v}_{\mathrm{p}}=\frac{4}{3} \pi \mathrm{r}_{\mathrm{p}}^{3}=\mathrm{n}_{\mathrm{p}} \Omega
$$

so that

$$
\frac{d V_{p}}{d t}=\Omega \frac{d n_{p}}{d t}=4 \pi r_{p}^{2} \frac{d r_{p}}{d t}
$$

Therefore, by the use of Equations (162) and (163), the following equation is obtained:

$$
\begin{aligned}
& \frac{d r_{p}}{d t}=-\frac{1}{r_{p}}\left[D_{i} C_{i}+D_{v}\right. \\
& \left.\left\{C_{o} \exp \left[\frac{\Omega}{k T}\left(\frac{2 \gamma}{r_{p}}+P-P_{q}\right)\right]-C_{v}\right\}\right] .
\end{aligned}
$$

The pressure of the gas in the pore, $\mathrm{P}_{\mathrm{q}}$ is calculated from a simplified van der Waals gas law and is given by

$$
P_{g}=\frac{n_{g} k T}{\left(\frac{4}{3} \pi r_{p}^{3}-\beta n_{g}\right)} .
$$

where $\beta$ is van der Waals gas constant and $n_{g}$ is the number of gas atoms in the pore. The change in the number of gas atoms in a pore with respect to time is given in Reference 12 by

$$
\frac{d n_{g}}{d t}=4 \pi r_{p} D C N_{o}-\frac{n_{g}}{\tau}
$$

where $D$ is the fission gas diffusion coefficient, and $\mathrm{C}$ is the fission gas concentration which is a function of temperature, depletion, grain size, etc. D and $C$ are the same as those used in Equation (22).

The first term on the right-hand side of Equation (166) is the rate at which gas migrates to the pore, and the second term is the rate at which it is knocked out by fission fragments passing through the pore.

Very early, $C$ is essentially zero; therefore, $n_{g}$ and $P_{g}$ are essentially zero and hence unimportant 
as far as calculating the change in the pore radius with respect to time. After a time $T$ (approximately 7 hours), Equation (166) reaches a steady state value; therefore, for the work reported herein, it is assumed that the gas is always in steady state in the pores so that

$$
\mathrm{n}_{\mathrm{g}}=4 \pi \mathrm{r}_{\mathrm{p}} \mathrm{DCN} \mathrm{N}_{\mathrm{o}} \tau
$$

At this point, there are four equations [Equations (154), (155), (161), and (164)] in four unknowns $\left(C_{v}, C_{i}, N_{d}\right.$, and $\left.I_{p}\right)$ which can be solved simultaneously. These equations must be combined with the swelling and gas release model to obtain C and D. Since the interstitials diffuse very rapidly at the temperature of interest here, it is assumed that they are in steady-state equilibrium; thus $\mathrm{dC}_{\mathrm{i}} / \mathrm{dt}$ can be set equal to zero. With $\mathrm{dC}_{\mathrm{i}} / \mathrm{dt}$ $=0$, Equations (154), (155), (161), and (164) were solved with the initial conditions that $C_{v}=C_{o}, N_{d}$ $=U$, and $r_{p}=10^{-4} \mathrm{~cm}$. It was found that, with the large production rate of interstitials $\left(10^{12} / \mathrm{cm}^{3} \mathrm{sec}-\right.$ ond with a fission rate $10^{13}$ fissions $/ \mathrm{cm}^{3}$ second) and with the somewhat smaller production rate of vacancies, the interstitials impose a steady-state concentration on the vacancies far sooner than if the vacancies approached steady state through their own diffusion. The vacancies reached steady state in less than a second at temperatures down to $200^{\circ} \mathrm{C}$. Because of the rapid approach of vacancies to steady state, $\mathrm{dC}_{\mathrm{v}} / \mathrm{dt}$ can also be set equal to zero.

Equations (154), (155), (161), and (164) were solved assuming both $\mathrm{dC}_{\mathrm{v}} / \mathrm{dt}$ and $\mathrm{dC}_{\mathrm{i}} / \mathrm{dt}$ equal zero.

Stehle and Assmann (Reference 19) have pointed out that when a fission fragment passes through a pore, the resulting disruption can "knock" vacancies from the pore to the lattice. Some of the vacancies diffuse away from the pore to other sinks and the pore shrinks. The exact details of such a knocking process are most likely very complicated and no attempt will be made here to discuss them. What is needed is an estimate of the number of times per second a pore is hit by a fission fragment and the number of vacancies that escape per hit (this will be called $\eta$ ). The number of hits per second is equal to the number of fission fragments produced per second, times the volume around each pore through which the fragment can travel and remove varancies from the pore, times the number of pores. The number of fission fragments produced per second is $2 f$ and the total volume in which they can cause vacancies to leave the pore is $4 \pi r_{p}^{2} N_{p} \lambda^{\prime}$, where $\lambda^{\prime}$ is the "viable" length of the fission fragment path. Immediately after a fragment is created, its energy is too great to cause displacements; however, during approximately the last 10 percent of the path length the energy is low enough to cause displace- ments. This.is the "viable" path length. Since the total path length is $10 \mu$, the "viable" path length is approximately $1 \mu$.

The probability that a particular pore is hit by a fragment is

$$
2 \dot{i} 4 \pi r_{p}^{2} \lambda^{\prime}
$$

If the number of vacancies knocked out of a pore per collision is $\eta$ (assumed to be approximately 100), then the number of vacancies knocked out of the pore per second is

$$
2 \dot{\mathrm{f}} 4 \pi \mathrm{r}_{\mathrm{p}}^{2} \lambda^{\prime} \eta \text {. }
$$

It is an easy matter to show that the change in the pore radius with respect to time is given by

$$
\frac{d r_{p}}{d t}=-\Omega 2 \dot{i} \lambda^{\prime} \eta
$$

The total change in the pore radius with rospect to time is now given by adding Equation (170) to Equation (164). The vacancy production rate from the pores is given by

$$
\frac{\mathrm{dC}_{\mathrm{v}}}{\mathrm{dt}}=8 \pi \dot{\mathrm{f}} \mathrm{r}_{\mathrm{p}}^{2} \lambda^{\prime} \eta \mathrm{N}_{\mathrm{p}} \Omega
$$

The vacancy production rate given by Equation (171) must now be added to Equation (154) to get the total change in the vacancy concentration with respect to time.

\section{K. Densification of Intergranular Porosity}

There are two types of intergranular porosity which are considered in this report: (1) interconnected, which has already been discussed, and (2) grain corner. Pores which occur between two grains will be assumed to behave as those in the corners. This is a good assumption since most intergranular porosity left over from densification occurs at the grain corners. Also, many of these pores are on the order of the grain size and hence must be in the corners.

The pores grow by absorbing vacancies and shrink by emitting vacancies and absorbing interstitials. To the point defects at the grain interior, the corner pores appear as part of the boundary. The interstitial concentration at the pore is zero and the vacancy concentration is given by

$$
C_{0} \exp \left[\frac{\Omega}{k T}\left(\frac{2 \gamma}{r_{p}^{\prime}}+P-P_{q}^{\prime}\right)\right]
$$


as opposed to $C_{0}$ as it is elsewhere on the boundary. In Equation (172), $r_{p}^{\prime}$ is the corner pore radius and $P_{g}^{\prime}$ is the pressure due to the fission gas that has migrated to the pores.

Using Equation (172), the rate at which vacancies diffuse from the grain interior to the pores can be calculated. It is assumed that the presence of a pore does not change the vacancy or interstitial concentration in the grains. It can be shown that the vacancy production rate due to fissioning is about 100 times larger than that due to vacancy knockout from the pores.

The net flux of vacancies into a pore per unit area of pore is given by

$$
\begin{aligned}
K_{v} D_{v} N_{o}\left\{C_{v}-C_{o}\right. \\
\left.\exp \left[\frac{\Omega}{k T}\left(\frac{2 \gamma}{\mathrm{r}_{\mathrm{p}}^{\prime}}+P-\mathrm{P}_{\mathrm{g}}^{\prime}\right)\right]\right\} .
\end{aligned}
$$

The net flux of vacancies into the pore is given by

$$
\begin{aligned}
4 \pi r_{p}^{2} N_{o} k_{v} D_{v}\left\{C_{v}-C_{o} .\right. \\
\left.\quad \exp \left[\frac{\Omega}{k T}\left(\frac{2 \gamma}{r_{p}^{\prime}}+P-P_{q}\right)\right]\right\} .
\end{aligned}
$$

In a similar fashion the net flux of interstitials into the pore from the grain interior is given by

$$
4 \pi r_{p}^{\prime 2} N_{o} k_{i} D_{i} C_{i}
$$

The net flux of vacancies into a pore from the grain interior is given by

$$
\begin{aligned}
\mathrm{J}_{1}= & -4 \pi \mathrm{r}_{\mathrm{p}}^{\prime 2} \mathrm{~N}_{\mathrm{o}}\left[\mathrm{k}_{\mathrm{i}} \mathrm{D}_{\mathrm{i}} \mathrm{C}_{\mathrm{i}}-\mathrm{k}_{\mathrm{v}} \mathrm{D}_{\mathrm{v}}\left\{\mathrm{C}_{\mathrm{v}}\right.\right. \\
& \left.\left.-\mathrm{C}_{\mathrm{o}} \exp \left[\frac{\Omega}{\mathrm{kT}}\left(\frac{2 \gamma}{\mathrm{r}_{\mathrm{p}}^{\prime}}+\mathrm{P}-\mathrm{P}_{\mathrm{q}}\right)\right]\right\}\right] .
\end{aligned}
$$

Vacancies can also migrate out of the pores along the grain boundaries. The vacancy flux per unit length of boundary in contact with a pore is given by

$$
j=D_{v_{g}} \frac{\Delta C}{\Delta x},
$$

where

$$
\Delta \mathrm{C}=\mathrm{C}_{\circ} \exp \left[\frac{\Omega}{\mathrm{kT}}\left(\frac{2 \gamma}{\mathrm{r}_{\mathrm{p}}^{\prime}}+\mathrm{P}-\mathrm{P}_{\mathrm{q}}^{\prime}\right)\right]-\mathrm{C}_{\mathrm{o}} \text {, }
$$

and $\Delta x$ is taken as the radius of a grain face, $R_{b i}$ $D_{v_{a}}$ is the vacancy diffusion coefficient in a region $\delta^{\prime}$ thick along the grain boundaries. $\mathrm{D}_{\mathrm{V}_{\mathrm{g}}}$ is related to the grain boundary self-diffusion coefficient by the equation

$$
\mathrm{D}_{\mathrm{gb}}=\mathrm{D}_{\mathrm{v}_{\mathrm{g}}^{\prime}} \mathrm{C}_{\circ}
$$

The number of vacancies that migrate out of the pore per second per unit length of boundary intersecting the pore is given by

$\mathrm{i}=\frac{\mathrm{N}_{\mathrm{o}} \cdot \mathrm{D}_{\mathrm{v}_{\mathrm{g}}} \delta^{\prime}\left\{\mathrm{C}_{\mathrm{o}} \exp \left[\frac{\Omega}{\mathrm{kT}}\left(\frac{2 \gamma}{\mathrm{r}_{\mathrm{p}}^{\prime}}+\mathrm{P}-\mathrm{P}_{\mathrm{g}}^{\prime}\right)\right]-\mathrm{C}_{\mathrm{o}}\right\}}{\mathrm{R}_{\mathrm{b}}}$

If it is assumed that the pore is spherical and is at the corner of four grains, then it can be shown that the total boundary line length intersecting the pore is $11.46 \mathrm{r}_{\mathrm{p}}^{\prime}$.

The net flux of vacancies out of the pore due to diffusion along the grain boundary per pore is given by

$\mathrm{J}_{2}=\frac{-11.46 \mathrm{r}_{\mathrm{p}} \mathrm{N}_{\mathrm{o}} \mathrm{D}_{\mathrm{gb}} \delta^{\prime}\left\{\exp \left[\frac{\Omega}{\mathrm{kT}}\left(\frac{2 \gamma}{\mathrm{r}_{\mathrm{p}}^{\prime}}+\mathrm{P}-\mathrm{P} \mathrm{g}\right)\right]-1\right\}}{\mathrm{R}_{\mathrm{b}}}$

Vacancies are also brought into the pores from gas bubbles migrating to the pores along the grain boundary edges. The rate at which gas atoms reach the pores is the same as the rate at which they migrate into the corner bubbles. Define $\dot{a}_{c}$ as the number of gas atoms that migrate to the corner bubbles per unit time. The number of vacancies arriving per gas atom is approximately $\beta / \Omega$. The number of vacancies arriving at the pore per second is given by

$$
\mathrm{J}_{3}=\frac{\beta}{\Omega} \dot{\mathrm{a}}_{\mathrm{c}} .
$$

The change in the radius with respect to time due to point defect diffusion is given by

$$
\frac{d r_{p}^{\prime}}{d t}=\frac{\Omega J}{4 \pi r_{p}^{\prime 2}}
$$

where $J$ is the net number of vacancies arriving at the pore per unit time and is the sum of $J_{1}, J_{2}$, and $J_{3}$. From Equation (170), the change in the pore radius due to vacancy knockout by fission fragments can be calculated. It was previously stated that the number of grain corners per $\mathrm{cm}^{3}$ is $0.695 /\left(R_{q}^{2} R_{b}\right)$. If there are $N_{p}^{\prime}$ grain boundary pores, then there can only be. $0.695 /\left(\mathrm{R}_{\mathrm{g}}^{2} \mathrm{R}_{\mathrm{b}}\right)-\mathrm{N}_{\mathrm{p}}^{\prime}$ grain corner bubbles. The corner swelling is then given by

$$
\begin{aligned}
\left.\frac{\Delta V}{V}\right|_{c}= & \frac{4}{3} \pi r_{c}^{3}\left(\frac{0.695}{R_{g}^{2} R_{b}}-N_{p}^{\prime}\right) \\
& +\frac{4}{3} \pi r_{c}^{\prime 3} N_{p}^{\prime} .
\end{aligned}
$$


When

$$
\left.\frac{\Delta V}{V}\right|_{c}+\left.\frac{\Delta V}{V}\right|_{e}
$$

is greater than 5 percent, then tunnels form. If the initial porosity due to corner pores is greater than 5 percent, then tunnels form immediately. When $r_{p}^{\prime}$ is less than $I_{c \prime}$ corner pores should be treated as corner bubbles. The amount of gas in a corner pore is the same as that in a corner bubble as given by Equation (132). The gas pressure in a corner pore is given by

$$
\mathrm{P}_{\mathrm{g}}^{\prime}=\frac{\mathrm{n}_{\mathrm{c}}^{\prime} \mathrm{kT}}{\left(\frac{4}{3} \pi \mathrm{r}_{\mathrm{p}}^{\prime 3}-\beta \mathrm{n}_{\mathrm{c}}\right)}
$$

\section{COMPARISONS WITH EXPERI- MENTAL DATA}

Theoretical predictions of gas release, swelling, and densification in both $\mathrm{ThO}_{2}$ and $\mathrm{UO}$, were obtained using the constants given in the Nomenclature. Figure 1 compares predicted gas release for $\mathrm{UO}_{2}$ with data of Lewis (Reference 20). The fission rate is $10^{13}$ fissions $/ \mathrm{cm}^{3}$ second. The temperature gradient is assumed to be $1000^{\circ} \mathrm{C} / \mathrm{cm}$ and the grain radius is assumed to be $10^{-3} \mathrm{~cm}$. To make the predictions, the radius of the fuel rods was divided into three equal lengths and the average temperature in each of the three regions was calculated assuming a fuel surface temperature of $400^{\circ} \mathrm{C}$. In most cases reasonable agreement is $\mathrm{nb}=$ tained between predictions and data.

Figure 2 shows the fission-gas release data of Zimmermann for $\mathrm{UO}_{2}-20 \% \mathrm{PuO}_{2}$ (Reference 21). The fission rate is $10^{14}$ fissions $/ \mathrm{cm}^{3}$ seoond. The maximum clad temperatures were between 44.3 and $690^{\circ} \mathrm{C}$. 'Limmermann provided average fuel temperatures. Using these temperatures and the clad surface temperatures, temperature profiles were constructed using assumed parabolic temperature profiles. A temperature gradient of $1000^{\circ} \mathrm{C} / \mathrm{cm}$ and a grain diameter between $\mathrm{l}$ and $2 \mu \mathrm{m}$ were used for the calculation. Three different sets of theoretical curves were generated using average fuel temperatures of 1000,1250 , and $1500^{\circ} \mathrm{C}$. In constructing Figure 2 , the same physical constants as those used for $\mathrm{UO}_{2}$ were $-\mathrm{m}$ ployed.

The theoretical predictions were also compared with the data of Hilbert et al. (Reference 22) for $\mathrm{UO}_{2}$; the results are shown in Table 1 and in Figure 3. The initial grain size was $10 \mu \mathrm{m}$ and the grains were equiaxed. The final grain size varied from $20 \mu \mathrm{m}$-diameter equiaxed grains to columnar grains $50 \mu \mathrm{m}$ diameter by approximately $800 \mu \mathrm{m}$ long at the highest temperatures. At the higher temperatures gas release was nearly 100 percent and swelling due to gas was approximately zero; consequently, results are presented assuming $10 \mu \mathrm{m}$-diameter and $50 \mu \mathrm{m}$-diameter grains and assuming that these limits adequately predict the limits of the observed conditions. Both theory and experiment show a decrease in swelling with temperature. It should be pointed out that the Hilbert et al. (Reference 22) temperatures are higher than the present model can accurately accommodate, since no allowance was made in the model for the columnar grain formation which occurred in their higher temperature regions.

Figure 4 shows the gas-release data of Bellamy and Rich (Reference 23) as a function of burnup. The $\mathrm{UO}_{2}$ specimens were irradiated at a fission rate of about $2 \times 10^{13}$ fissions $/ \mathrm{cm}^{3}$ second and had a grain radius of $7.5 \mu \mathrm{m}$. The center line temperatures were, on the average, about $1200^{\circ} \mathrm{C}$ and the fuel surface temperatures were approximately $600^{\circ} \mathrm{C}$. Fuol center line lempẹıalures of a few spccitic specimens dst shown in Figurs 4. Also shown are the model predictions assuming center line temperatures of 800,1200 , and $1400^{\circ} \mathrm{C}$ with a surface temperature of $600^{\circ} \mathrm{C}$.

Comparisons have been made between the model and the data of Freshley et al. (Reference 24 ). The results are shown in Table 2 . The pellets were $0.92 \mathrm{~cm}$ diameter. The fuel surface temperature was taken as $550^{\circ} \mathrm{C}$ when the center line temperature exceeded $550^{\circ} \mathrm{C}$. In making the predictions, it was assumed that the small pores were intragranular and that the large pores were on the gain boundaries. The predicted density changes versus the observed density changes are plotted in Figure 5. The majority of the predictions are within 2 percent of the observed changes; however, in some cases the predictions result in a positive $\Delta \rho$ while the measurements indicate some swelling. On the whole, the model predicts a little more donoification than that uluserved by Freshley et al. (Reference 24).

Comparisons were also made between the model and the data of Banks (Reference 25). The results are shown in Table 3 . Table 4 shows the initial porosity for each of the spooimen types. The small pores are assumed to be $2 \mu \mathrm{m}$ diameter and the large porcs $10 \mu \mathrm{m}$ diameler. The pellets were $1.45 \mathrm{~cm}$ diameter. A fuel surface temperature of $500^{\circ} \mathrm{C}$ was assumed when the center line temperatures exceeded $500^{\circ} \mathrm{C}$. The predicted volume incroanc above 100 percent dense fuel versus the observed volume increase for Banks' specimens are shown in Figure 6. Almost all of the predictions are within 2 percent of the observed results.

The model was also compared with densification data of Ross (Rofcrence 26). Russ irradiated $\mathrm{UO}_{2}$ at $200^{\circ} \mathrm{C}$ and observed that pores up to $0.5 \mu \mathrm{m}$ diameter were removed after irradiation of $3 \times 10^{19}$ fissions $/ \mathrm{cm}^{3}$. The model here predicts complete densification by depletion of 1 $\times 10^{19}$ fissions $/ \mathrm{cm}^{3}$. Ross also observed that most 
$0.3 \mu \mathrm{m}$-diameter pores were removed by a burnup of $3.0 \times 10^{18}$ fissions $/ \mathrm{cm}^{3}$. The model predicts complete densification by $3.2 \times 10^{18} \mathrm{fis}-$ sions $/ \mathrm{cm}^{3}$. The model is, therefore, in good agreement with the Ross data.

A thoria specimen was irradiated at a center line temperature of $1470^{\circ} \mathrm{C}$ and with a surface temperature of $570^{\circ} \mathrm{C}$ to a depletion of $3.5 \times 10^{20} \mathrm{fis}-$ sions $/ \mathrm{cm}^{3 *}$. The initial density was 93 percent. The initial grain size was about $4.5 \times 10^{-3} \mathrm{~cm}$. The initial average pore size was about $2 \mu \mathrm{m}$ diameter. Under these conditions, the volume was observed to decrease. 2.9 percent. The model predicts a decrease of 4 percent. Under the above conditions, it was observed that 1 percent of the fission gas generated was released. The model predicts 2.5 percent. The model also predicts complete closure of the fabricated pores.

Another thoria rod, 81-90**, was fissioned to a depletion of $2 \times 10^{19}$ fissions $/ \mathrm{cm}^{3}$ at a fission rate of about $3.4 \times 10^{12}$ fissions $/ \mathrm{cm}^{3}$ second. The center line temperature of the fuel was about $427^{\circ} \mathrm{C}$ and the surface temperature was about $367^{\circ} \mathrm{C}$. The grain size was $7 \mu \mathrm{m}$, and the initial porosity was 2.6 percent. The final porosity measured experimentally was 1.4 percent; the model predicts 2 percent. There was no gas release observed experimentally or predicted by the model. It was assumed that 0.26 percent of the initial porosity was in the form of $2 \mu \mathrm{m}$-diameter pores and that 2.34 percent of the initial porosity was in the form of $6 \mu \mathrm{m}$-diameter pores. The latter pores were assumed to be on the grain boundaries. In the case of the Waldman specimen, the model predicts slightly more densification than that observed and in the case of the Spahr specimen the model predicts less densification that that observed.

\section{SUMMARY AND CONCLU- SIONS}

A model was developed to predict the migratory behavior of fission-induced gas in oxide fuels. The model can predict gas bubble size and density in the grain interior and on grain boundaries, grain edges, and corners. The model includes resolution effects and restricted bubble motion, both random and along thermal gradients. The resulting swelling is predicted. Gas release from tunnels along the grain edges is also calculated.

The model was also developed to predict intragranular and intergranular densification. The model treats both densification due to thermal diffusion of point defects and pore destruction due to fission fragment passage through the pores.

Comparisons were made between the gas release data of Lewis (Reference 20), Zimmermann (Reference 21), Hilbert et al. (Reference 22),
Bellamy and Rich (Reference 23) and theory with good agreement. Comparisons were also made between theory and the swelling data of Hilbert et al. (Reference 22), Freshley et al. (Reference 24), Banks (Reference 25), Ross (Reference 26), Waldman, and Spahr with good agreement.

\section{ACKNOWLEDGMENTS}

The author wishes to express his appreciation to E. Duncombe, E. A. Zanoni, and F. A. Nichols for their many helpful comments; also to L. A. Waldman and G. L. Spahr for making $\mathrm{ThO}_{2}$ experimental data available.

\section{REFERENCES}

1. C. C. Dollins and H. Ocken, "'A Fission Gas Swelling Model Incorporating Re-solution Effects," Nucl. Appl. and Tech. 9, 141 (1970) and WAPD-TM-962, July 1971.

2. A. C. Damask and G. J. Dienes; Point Defects in Metals, p. 82, Gordon and Breach, New York, 1963.

3. C. C. Dollins, "Fission Gas Swelling and Long-Range Migration at Low Temperatures," J. Nucl. Mater., 49, 10 (1973) and WAPD-TM-1 124, January 1974.

4. B. J. Buescher and R. O. Meyer, "ThermalGradient Migration of Helium Bubbles in Uranium Dioxide," J. Nucl. Mater., 48, 143 (1973).

5. D. Davies and G. Long, "The Emission of Xenon-133 from Lightly Irradiated Uranium Dioxide Spheroids and Powders," Rpt. U. K. Atomic Energy Auth., AERE-R-4347, (1963).

6. R. S. Nelson, "The Stability of Gas Bubbles in an Irradiation Environment," J. Nucl. Mater., 31,153 (1969).

7. C. C. Dollins and F. A. Nichols, "Swelling and Gas Release in $\mathrm{UO}_{2}$ at Low and Intermediate Temperatures," J. Nucl. Mater., 60, 138 (1976).

8. A. Dvoretzky and P. Erdos, "Some Problems on Random Walk in Space," in Proc. 2nd Berkeley Symposium on Mathematical Statistics and Probability, ed. by J. Newyman, University of Calif. Press, Berkeley, p. 353, 1951.

9. G. H. Vineyard, "The Number of Distinct Sites Visited in a Random Walk on a Lattice," J. of Mathematical Phys., 4, 1191 (1963).

10. J. A. Turnbull and M. O. Tucker, "Swelling in $\mathrm{UO}_{2}$ Under Conditions of Gas Release," Phil. Mag., 30, 47 (1974).

11. F. A. Nichols, "On the Diffusional Mobilities of Particles, Pores, and Loops," Acta Met., 20, 207 (1972).

\footnotetext{
-Information obtained from L. A. Waldman, Bettis Atomic Power Laboratory, October, 1976.

- Information obtained from G. L. Spahr, Bettis Atomic Power Laboratory, January, 1977.
} 
12. C. C. Dollins and F. A. Nichols, "In-pile Intragranular Densification of Oxide Fuels (AWBA Development Program)," WAPDTM-1293, October 1977.

13. S. R. MacE'wen and I. J. Hastings, "A Model for In-Reactor Densification of $\mathrm{UO}_{2}$, "Phil. Mag., 31, i35 (1975).

14. C. C. Dollins, "In-pile Dimensional Changes in Neutron Irradiated Zirconium Base Alloys," J. Nucl. Mater, 59, 61 (1975).

15. H. R. Warner and F. A. Nichols, "A Statistical Fuel Swelling and Fission Gas Release Model," Nucl. Appl. and Tech., 9, 148 (1970) and WAPD-TM-942, September 1970.

16. A. D. Brailsford and R. Bullough, "Swelling of Irradiated Materials," in Physical Metallurgy of Reactor Fuel Elements, p. 148, The Metals Society, 1975.

17. F. S. Ham, "Stress-Assisted Precipitation on Dislocations," J. of Appl. Physicis, 30, 915 (1959).

18. S. D. Harkness and C. Y. Li, "A Study of Void Formation in Fast Neutron-Irradiated Metals," Met. Truns., 2, 1457 (1971).

19. H. Stehle and H. Assmann, "The Dependence of In-Reactor $\mathrm{UO}_{2}$ Densification on
Temperature and Microstructure," J. Nucl. Mater., 52, 303 (1974).

20. W. B. Lewis, "Engineering for the Fission Gas in $\mathrm{UO}_{2}$ Fuel, $^{\prime \prime}$ Nucl. App., 2, 171 (1966).

21. H. Zimmermann, "Fission Gas Behavior in Oxide Fuel Elements of Fast Breeder Reactors," Nucl. Tech., 28, 127 (1976).

22. R. F. Hilbert, V. W. Storhok, W. Chubb, and D. L. Keller, "Mechanisms of Swelling and Gas Release in Uranium Dioxide," J. Nucl., Mater., 38, 26 (1971).

23. R. G. Bellamy and J. B. Rich, "GrainBoundary Gas Release and Swelling in High Burnup Uranium Dioxide," J. Nucl. Mater., 33, 64 (1969)

24. M. D. Freshley, D. W. Brite, J. L. Daniel, and P. E. Hart, "Irradiation-Induced Densification of $\mathrm{UO}_{2}$ Pellet Fuel," J, Nucl. Mater., 62, 138 (1976)

25. D. A. Banks, "Some Observations of Density and Porrosity Changes in $U \Omega_{2}$ Finel Irradiated in Water-Cooled Reactors," J. of Nucl. Mater., 54, 97 (1974).

26. A. M. Ross, "Irradiation Behavior of FissionGas Bubbles and Sintering Pores in $\mathrm{UO}_{2}, " J$. Nucl. Mater., 30, 134 (1969). 
TABLE 1. SWELLING AND GAS RELEASE DATA OF HILBERT et al.

\begin{tabular}{|c|c|c|c|c|c|c|}
\hline \multirow{2}{*}{$\begin{array}{c}\text { Burnup } \times 10^{-20} \\
\text { fissions } / \mathrm{cm}^{3}\end{array}$} & \multirow{2}{*}{$\begin{array}{l}\text { Center Line } \\
\text { Temperature, } \\
{ }^{\circ} \mathrm{C}\end{array}$} & \multirow{2}{*}{$\begin{array}{c}\text { Fuel Surface } \\
\text { Temperature, } \\
{ }^{\circ} \mathrm{C}\end{array}$} & \multicolumn{2}{|c|}{$\frac{\Delta \mathrm{V}}{\mathrm{V}}$, Swelling, \% } & \multicolumn{2}{|c|}{ Gas Release, \% } \\
\hline & & & Measured & Predicted & Measured & Predicted \\
\hline 2.3 & 2190 & 1825 & 5 & $5.5-6$ & $90-100$ & $97-99$ \\
\hline 1.7 & 1855 & 1475 & 10 & $5.6-9.2$ & 90 & $94-95$ \\
\hline 2.25 & 2030 & 1620 & 5 & $5.8-7.9$ & 90 & $96.8-98$ \\
\hline 2.45 & 2000 & 1630 & - & $5.9-8.3$ & 90 & $97-98$ \\
\hline 1.85 & 2050 & 1490 & 8 & $5.7-7.3$ & 80 & 96 \\
\hline 1.75 & 1660 & 1310 & 10 & $5.6-9.4$ & 75 & $71-87$ \\
\hline
\end{tabular}

TABLE 2. COMPARISONS BETWEEN MODEL AND DATA OF FRESHLEY et al.

Type 1 fuel, grain size $=3 \mu \mathrm{m}$, small pore size $=0.4 \mu \mathrm{m}$, small pore volume $=6.3 \%$, large pore size $=2.0 \mu \mathrm{m}$, large pore volume $=1.3 \% \pm 0.2$

\begin{tabular}{|c|c|c|c|c|c|}
\hline \multirow[b]{2}{*}{ Pin Location } & \multirow{2}{*}{$\begin{array}{c}\text { Fission Rate } \\
\left(\mathrm{cm}^{3} \mathbf{s e c}\right)^{-1}\end{array}$} & \multirow{2}{*}{$\begin{array}{l}\text { Center Line } \\
\text { Temperature, } \\
{ }^{\circ} \mathrm{C}\end{array}$} & \multirow{2}{*}{$\begin{array}{l}\text { Burnup } \\
\text { MWd/MTM }\end{array}$} & \multicolumn{2}{|c|}{ Average $\Delta \rho \%$} \\
\hline & & & & Measured & Predicted \\
\hline A-85 & $3.4 \times 10^{12}$ & 310 & 224 & 0.48 & \\
\hline A-86 & $3.2 \times 10^{12}$ & 300 & 214 & 0.66 & \\
\hline A-11 & $9.6 \times 10^{12}$ & 910 & 646 & 5.41 & \\
\hline A-12 & $1.01 \times 10^{13}$ & 955 & 677 & 5.30 & \\
\hline A-49 & $1.29 \times 10^{13}$ & 1235 & 860 & & \\
\hline A-50 & $1.25 \times 10^{13}$ & 1200 & 839 & 0.40 & 4.5 \\
\hline B-85 & $3.4 \times 10^{12}$ & 310 & 815 & 1.86 & \\
\hline B-86 & $3.2 \times 10^{12}$ & 300 & 792 & 1.17 & \\
\hline B-1 1 & $9.6 \times 10^{12}$ & 910 & 2335 & 6.67 & 0 \\
\hline B-12 & $1.01 \times 10^{13}$ & 955 & 2462 & 5.88 & 0.0 \\
\hline B-49 & $1.24 \times 10^{13}$ & 1190 & 2996 & 7.13 & \\
\hline B-50 & $1.24 \times 10^{13}$ & 1190 & 2996 & 7.12 & 0.8 \\
\hline
\end{tabular}


Type 2 fuel, grain size $=4 \mu \mathrm{m}$, small pore size $=0.6 \mu \mathrm{m}$, small pore volume $=6.8 \%$, large pore size $=3.0 \mu \mathrm{m}$, large pore volume $2.4 \pm 0.4 \%$

\begin{tabular}{|c|c|c|c|c|c|}
\hline \multirow[b]{2}{*}{ Pin Location } & \multirow{2}{*}{$\begin{array}{c}\text { Fission Rate } \\
\left(\mathrm{cm}^{3} \mathrm{sec}\right)^{-1}\end{array}$} & \multirow{2}{*}{$\begin{array}{c}\text { Center Line } \\
\text { Temperature, } \\
{ }^{\circ} \mathrm{C}\end{array}$} & \multirow{2}{*}{$\begin{array}{c}\text { Burnup } \\
\text { MWd/MTM }\end{array}$} & \multicolumn{2}{|c|}{ Average $\Delta \rho \%$} \\
\hline & & & & Measured & Predicted \\
\hline A-72 & $6.6 \times 10^{12}$ & 610 & 437 & 0.96 & ) \\
\hline A-73 & $6.3 \times 10^{12}$ & 580 & 417 & 0.82 & \\
\hline A-45 & $1.35 \times 10^{13}$ & 1295 & 895 & 5.22 & 4.4 \\
\hline B-72 & $6.4 \times 10^{12}$ & 600 & 1583 & 2.40 & ) \\
\hline B-73 & $6.3 \times 10^{12}$ & 585 & 1520 & 1.71 & \\
\hline$B=45$ & $1.32 \times 10^{13}$ & 1265 & 3190 & 6.19 & \\
\hline B-47 & $1.27 \times 10^{13}$ & 1220 & 3083 & 6.17 & \\
\hline
\end{tabular}

Type 3 fuel, grain size $=14 \mu \mathrm{m}$, small pore size $=1.2 \mu \mathrm{m}$, small pore volume $=1.2 \%$, large pore size $=1.5 \mu \mathrm{m}$, large pore volume $=4.1 \pm 0.4 \%$

\begin{tabular}{|c|c|c|c|c|c|}
\hline \multirow[b]{2}{*}{ Pin Location } & \multirow{2}{*}{$\begin{array}{c}\text { Fission Rate } \\
\left(\mathrm{cm}^{3} \mathrm{sec}\right)^{-1}\end{array}$} & \multirow{2}{*}{$\begin{array}{c}\text { Center Line } \\
\text { Temperature, } \\
{ }^{\circ} \mathrm{C}\end{array}$} & \multirow{2}{*}{$\begin{array}{c}\text { Burnup } \\
\text { MWd/MTM }\end{array}$} & \multicolumn{2}{|c|}{ Average $\Delta \rho \%$} \\
\hline & & & & Measured & Predicted \\
\hline A-77 & $5.2 \times 10^{-12}$ & 470 & 344 & -0.47 & ) \\
\hline A-79 & $4.7 \times 10^{12}$ & 425 & 318 & -0.65 & 1.0 \\
\hline A-55 & $1.16 \times 10^{13}$ & 1080 & 776 & 0.05 & \\
\hline A-56 & $1.13 \times 10^{13}$ & 1050 & 755 & 0.16 & \\
\hline A.37 & $1.41 \times 10^{13}$ & 1325 & 943 & 0.82 & ) \\
\hline A-38 & $1.41 \times 10^{13}$ & 1325 & 943 & 0.33 & 2.6 \\
\hline B-78 & $4.9 \times 10^{12}$ & $44 n$ & 1199 & $=0.45$ & ) \\
\hline B-79 & $4.9 \times 10^{12}$ & 440 & 1179 & -0.46 & 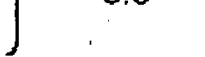 \\
\hline B-37 & $1.41 \times 10^{13}$ & 1320 & 3403 & 0.84 & ] \\
\hline B-38 & $1.41 \times 10^{13}$ & 1320 & 3.397 & 0.58 & 6. \\
\hline
\end{tabular}


TABLE 2 (Cont)

Type 4 fuel, grain size $=5 \mu \mathrm{m}$, small pore size $=0.5 \mu \mathrm{m}$, small pore volume $=6.3 \%$, large pore size $=2.0 \mu \mathrm{m}$, large pore volume $=0.6 \pm 0.3 \%$.

\begin{tabular}{|c|c|c|c|c|c|}
\hline \multirow[b]{2}{*}{ Pin Location } & \multirow{2}{*}{$\begin{array}{l}\text { Fission Rate } \\
\left(\mathrm{cm}^{3} \mathrm{sec}\right)^{-1}\end{array}$} & \multirow{2}{*}{$\begin{array}{c}\text { Center Line } \\
\text { Temperature, } \\
{ }^{\circ} \mathrm{C}\end{array}$} & \multirow{2}{*}{$\begin{array}{c}\text { Burnup } \\
\text { MWd/MTM }\end{array}$} & \multicolumn{2}{|c|}{ Average $\Delta \rho \%$} \\
\hline & & & & Measured & Predicted \\
\hline A-69 & $7.7 \times 10^{12}$ & 675 & 505 & 2.29 & \\
\hline A-70 & $7.0 \times 10^{12}$ & 640 & 474 & 1.99 & \\
\hline A-43 & $1.41 \times 10^{13}$ & 1325 & 937 & 5.08 & \\
\hline A-44 & $1.38 \times 10^{13}$ & 1290 & 916 & 5.04 & 7.4 \\
\hline B-8l & $4.3 \times 10^{12}$ & 380 & 1049 & 1.74 & 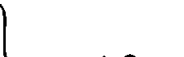 \\
\hline B-82 & $4.1 \times 10^{12}$ & 370 & 1005 & 1.63 & \\
\hline B-69 & $7.8 \times 10^{12}$ & 710 & 1884 & 4.21 & \\
\hline $\mathrm{B}-70$ & $7.3 \times 10^{12}$ & 670 & 1797 & 4.13 & \\
\hline B-43 & $1.36 \times 10^{13}$ & 1275 & 3290 & 5.25 & \\
\hline B-44 & $1.35 \times 10^{13}$ & 1260 & 3253 & 5.18 & \\
\hline
\end{tabular}

Type 5 fuel, grain size $=1.6 \mu \mathrm{m}$, small pore size $=0.4 \mu \mathrm{m}$, small pore volume $=1.5 \%$, large pore size $=13 \mu \mathrm{m}$, large pore volume $=7.2 \pm 0.7 \%$.

\begin{tabular}{|c|c|c|c|c|c|}
\hline \multirow[b]{2}{*}{ Pin Location } & \multirow{2}{*}{$\begin{array}{c}\text { Fission Rate } \\
\left(\mathrm{cm}^{3} \mathrm{sec}\right)^{-1}\end{array}$} & \multirow{2}{*}{$\begin{array}{c}\text { Center Line } \\
\text { Temperature, } \\
{ }^{\circ} \mathrm{C}\end{array}$} & \multirow{2}{*}{$\begin{array}{l}\text { Burnup } \\
\text { MWd/MTM }\end{array}$} & \multicolumn{2}{|c|}{ Average $\Delta \rho \%$} \\
\hline & & & & Measured & Predicted \\
\hline A-1 & $6.1 \times 10^{12}$ & 550 & 406 & -0.38 & ). \\
\hline A-3 & $6.9 \times 10^{12}$ & 625 & 458 & -0.33 & 1.1 \\
\hline A-27 & $1.36 \times 10^{13}$ & 1270 & 906 & 0.08 & \\
\hline $\bar{A}-2 \overline{8}$ & $1.36 \times 10^{1.3}$ & 1270 & .911 & -0.06 & .1 .0 \\
\hline B-1 & $6.0 \times 10^{12}$ & 555 & 1433 & -0.58 & \\
\hline B-3 & $6.6 \times 10^{12}$ & 600 & 1583 & -0.37 & \\
\hline$B=27$ & $1.32 \times 10^{13}$ & 1230 & 3210 & -0.44 & \\
\hline B-28 & $1.35 \times 10^{13}$ & 1260 & 3277 & -0.27 & \\
\hline
\end{tabular}


TABLE 2 (Cont)

Type 6 fuel, grain size $=22 \mu \mathrm{m}$, small pore size $=0.6 \mu \mathrm{m}$, small pore volume $=1.9 \%$, large pore size $=9.0 \mu \mathrm{m}$, large pore volume $=5.0 \pm 0.4 \%$.

\begin{tabular}{|c|c|c|c|c|c|}
\hline \multirow[b]{2}{*}{ Pin Location } & \multirow{2}{*}{$\begin{array}{c}\text { Fission Rate } \\
\left(\mathrm{cm}^{3} \mathrm{sec}\right)^{-1}\end{array}$} & \multirow{2}{*}{$\begin{array}{c}\text { Center Line } \\
\text { Temperature, } \\
{ }^{\circ} \mathrm{C}\end{array}$} & \multirow{2}{*}{$\begin{array}{c}\text { Burnup } \\
\text { MWd/MTM }\end{array}$} & \multicolumn{2}{|c|}{ Average $\Delta \rho \%$} \\
\hline & & & & Measured & Predicted \\
\hline A-4 & $6.9 \times 10^{12}$ & 640 & 468 & -0.46 & \\
\hline$A-6$ & $8.0 \times 10^{12}$ & 725 & 526 & -0.39 & 1.6 \\
\hline A-30 & $1.39 \times 10^{13}$ & 1300 & 932 & 0.30 & $\therefore$ \\
\hline$A-31$ & $1.41 \times 10^{13}$ & 1325 & 937 & -0.07 & \\
\hline B-4 & $6.9 \times 10^{12}$ & 625 & 1660 & -0.42 & \\
\hline B-6 & $7.7 \times 10^{12}$ & 695 & 1864 & -0.42 & \\
\hline B-58 & $1.1 \times 10^{13}$ & 1020 & 2675 & -0.04 & ). \\
\hline B-60 & $9.9 \times 10^{12}$ & 810 & 2418 & $-U .24$ & 2.5 \\
\hline B-61 & $9.9 \times 10^{12}$ & 910 & 2398 & 0.00 & \\
\hline B-30 & $1.36 \times 10^{13}$ & 1275 & 3320 & 0.04 & \\
\hline B-31 & $1.38 \times 10^{13}$ & 1290 & 3340 & -0.10 & 2.0 \\
\hline
\end{tabular}

Type 7 fuel, grain size $=24 \mu \mathrm{m}$, small pore size $=0.6 \mu \mathrm{m}$, small pore volume $=1.8 \%$, large pore size $=30 \mu \mathrm{m}$, large pore volume $=5.7 \pm 0.4 \%$.

\begin{tabular}{|c|c|c|c|c|c|}
\hline \multirow[b]{2}{*}{ Pin Location } & \multirow{2}{*}{$\begin{array}{c}\text { Fission Rate } \\
\left(\mathrm{cm}^{3} \text { ser }\right)^{-1}\end{array}$} & \multirow{2}{*}{$\begin{array}{l}\text { Center Line } \\
\text { Temperature, } \\
{ }^{\circ} \mathrm{C}\end{array}$} & \multirow{2}{*}{$\begin{array}{l}\text { Burnup } \\
\text { MWd/MTM }\end{array}$} & \multicolumn{2}{|c|}{ Average $\Delta \rho \%$} \\
\hline & & & & Measured & Predicted \\
\hline A-66 & $8.3 \times 10^{12}$ & 750 & 553 & -0.07 & - \\
\hline A- 67 & $8.3 \times 10^{12}$ & 750 & 547 & -0.20 & \\
\hline A-40 & $1.41 \times 10^{13}$ & 1325 & 943 & 0.26 & \\
\hline$A-41$ & $1.42 \times 10^{13}$ & 1325 & 948 & 0.40 & \\
\hline B-88 & $2.8 \times 10^{12}$ & 250 & 685 & -0.55 & \\
\hline R.89 & $3.8 \times 10^{1.2}$ & 250 & 665 & -0.73 & 1.0 \\
\hline B-90 & $2.6 \times 10^{12}$ & 240 & 621 & -0.73 & נק \\
\hline B-65 & $8.9 \times 10^{12}$ & 810 & 2141 & -0.32 & \\
\hline B-67 & $8.4 \times 10^{12}$ & 770 & 2.034 & -0.17 & \\
\hline B-40 & $1.39 \times 10^{13}$ & 1300 & 3360 & 0.48 & \\
\hline$B-41$ & $1.36 \times 10^{13}$ & 1275 & 3297 & -0.03 & 0.1 \\
\hline
\end{tabular}


TABLE 2 (Cont)

Type 8 fuel, grain size $=23 \mu \mathrm{m}$, small pore size $=0.6 \mu \mathrm{m}$, small pore volume $=1.5 \%$, large pore size $=2.1 \mu \mathrm{m}$, large pore volume $=1.3 \pm 0.3 \%$

\begin{tabular}{|c|c|c|c|c|c|}
\hline \multirow[b]{2}{*}{ Pin Location } & \multirow{2}{*}{$\begin{array}{c}\text { Fission Rate } \\
\left(\mathrm{cm}^{3} \mathrm{sec}^{-1}\right.\end{array}$} & \multirow{2}{*}{$\begin{array}{c}\text { Center Line } \\
\text { Temperature, } \\
{ }^{\circ} \mathrm{C}\end{array}$} & \multirow{2}{*}{$\begin{array}{c}\text { Burnup } \\
\text { MWd/MTM }\end{array}$} & \multicolumn{2}{|c|}{ Average $\Delta \rho \%$} \\
\hline & & & & Measured & Predicted \\
\hline A-74 & $6.1 \times 10^{12}$ & 535 & 406 & -0.19 & ) \\
\hline A-76 & $5.4 \times 10^{12}$ & 465 & 359 & -0.27 & 0.0 \\
\hline A-33 & $1.44 \times 10^{13}$ & 1320 & 958 & 0.23 & 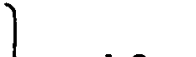 \\
\hline A-34 & $1.45 \times 10^{13}$ & 1330 & 974 & -0.11 & 1.0 \\
\hline B-75 & $6.0 \times 10^{12}$ & 520 & 1433 & -0.42 & \\
\hline B-76 & $5.7 \times 10^{12}$ & 490 & 1369 & -0.38 & \\
\hline B-33 & $1.39 \times 10^{13}$ & 1270 & 3360 & 0.00 & . \\
\hline B-34 & $1.41 \times 10^{13}$ & 1290 & 3427 & -0.06 & \\
\hline
\end{tabular}

Type 9 fuel, grain size $=29 \mu \mathrm{m}$, small pore size $=0.6 \mu \mathrm{m}$, small pore volume $=1.5 \%$, large pore size $=2.1 \mu \mathrm{m}$, large pore volume $=1.3 \pm 0.3 \%$.

\begin{tabular}{|c|c|c|c|c|c|}
\hline \multirow[b]{2}{*}{ Pin Location } & \multirow{2}{*}{$\begin{array}{c}\text { Fission Rate } \\
\left(\mathrm{cm}^{3} \mathrm{sec}\right)^{-1}\end{array}$} & \multirow{2}{*}{$\begin{array}{c}\text { Center Line } \\
\text { Temperature, } \\
{ }^{\circ} \mathrm{C}\end{array}$} & \multirow{2}{*}{$\begin{array}{c}\text { Burnup } \\
\text { MWd/MTM }\end{array}$} & \multicolumn{2}{|c|}{ Average $\Delta \rho \%$} \\
\hline & & & & Measured & Predicted \\
\hline A-7 & $8.7 \times 10^{12}$ & 770 & 578 & -0.24 & ) \\
\hline A-9 & $9.3 \times 10^{12}$ & 830 & 619 & -0.17 & \\
\hline A-5l & $1.27 \times 10^{13}$ & 1150 & 844 & 0.20 & $\cdot$ \\
\hline A-53 & $1.24 \times 10^{13}$ & 1120 & 823 & 0.22 & \\
\hline B-7 & $8.3 \times 10^{12}$ & 730 & 2014 & -0.10 & ) \\
\hline B-9 & $9.2 \times 10^{12}$ & 815 & 2228 & 0.05 & \\
\hline B-52 & $1.21 \times 10^{13}$ & 1090 & 2946 & 0.03 & \\
\hline B-53 & $1.21 \times 10^{13}$ & 1090 & 2946 & 0.16 & \\
\hline
\end{tabular}


TABLE 3. COMPARISONS BETWEEN MODEL AND DATA OF BANKS

\begin{tabular}{|c|c|c|c|c|c|}
\hline \multirow[b]{2}{*}{ Cluster } & \multirow{2}{*}{$\begin{array}{c}\text { Irradiation } \\
\text { Time, EFPD }\end{array}$} & \multirow{2}{*}{$\begin{array}{c}\text { Burnup } \times 10^{20} \\
\text { fissions } / \mathrm{cm}^{3}\end{array}$} & \multirow{2}{*}{$\begin{array}{c}\text { Center Line } \\
\text { Temporature, } \\
{ }^{\circ} \mathbf{C}\end{array}$} & \multicolumn{2}{|c|}{$\frac{\Delta \mathrm{V}}{\mathrm{V}}$, Swelling, $\%$} \\
\hline & & & & Observed & Predicted \\
\hline E $11 / 2$ & 660 & $\begin{array}{l}0.88 \\
2.65 \\
3.82\end{array}$ & $\begin{array}{r}460 \\
850 \\
1040\end{array}$ & $\begin{array}{l}3.19 \\
3.10 \\
2.74\end{array}$ & $\begin{array}{l}2.7 \\
2.6 \\
4.9\end{array}$ \\
\hline $\mathrm{L} 09 / 2$ & 385 & $\begin{array}{l}0.51 \\
1.56 \\
2.58 \\
3.12 \\
3.26\end{array}$ & $\begin{array}{r}480 \\
860 \\
1270 \\
1500 \\
1560\end{array}$ & $\begin{array}{l}2.83 \\
1.73 \\
2.28 \\
2.83 \\
3.01\end{array}$ & $\begin{array}{l}2.3 \\
1.7 \\
4.4 \\
4.7 \\
4.8\end{array}$ \\
\hline Q03/2 & 365 & $\begin{array}{l}0.98 \\
1.58 \\
2.45 \\
2.94 \\
3.15\end{array}$ & $\begin{array}{l}1090 \\
1370 \\
1712 \\
2160 \\
2170\end{array}$ & $\begin{array}{l}1.64 \\
3.38 \\
3.74 \\
6.2 \\
5.75\end{array}$ & $\begin{array}{l}2.9 \\
4.4 \\
4.7 \\
6.0 \\
6.3\end{array}$ \\
\hline $\mathrm{L} 05 / 2$ & 360 & $\begin{array}{l}0.09 \\
0.09 \\
0.18 \\
0.28 \\
0.37 \\
0.44 \\
0.49 \\
0.49 \\
0.49\end{array}$ & $\begin{array}{l}360 \\
360 \\
390 \\
410 \\
460 \\
460 \\
500 \\
480 \\
500\end{array}$ & $\begin{array}{l}3.56 \\
3.56 \\
3.65 \\
3.74 \\
3.74 \\
2.92 \\
3.56 \\
3.28 \\
3.28\end{array}$ & $\begin{array}{l}3.1 \\
3.7 \\
3.7 \\
3.7 \\
3.0 \\
\\
2.9\end{array}$ \\
\hline $\mathrm{L} 05 / 2$ & 360 & $\begin{array}{l}0.63 \\
0.68 \\
0.75 \\
0.86 \\
0.98 \\
1.07 \\
1.12 \\
1.37 \\
2.28 \\
2.75 \\
3.03\end{array}$ & $\begin{array}{r}550 \\
560 \\
600 \\
620 \\
660 \\
700 \\
720 \\
1133 \\
1573 \\
1709 \\
1796\end{array}$ & $\begin{array}{l}3.28 \\
3.38 \\
3.19 \\
3.10 \\
3.01 \\
3.28 \\
3.19 \\
3.56 \\
8.03 \\
7.48 \\
7.12\end{array}$ & $\begin{array}{l}2.9 \\
2.8 \\
2.7 \\
2.7 \\
2.7 \\
2.6 \\
2.7 \\
3.4 \\
4.6 \\
5.2 \\
5.6\end{array}$ \\
\hline $\begin{array}{l}\text { IFA29 } \\
\text { Sulid } \\
\text { Pellets }\end{array}$ & 420 & $\begin{array}{l}3.05 \\
3.33 \\
3.68 \\
4.40 \\
4.98 \\
5.43 \\
5.79\end{array}$ & $\begin{array}{l}1100 \\
1200 \\
1360 \\
1580 \\
1790 \\
2000 \\
2120\end{array}$ & $\begin{array}{l}3.28 \\
3.10 \\
3.56 \\
4.23 \\
4.74 \\
4.84 \\
5.47\end{array}$ & $\begin{array}{l}3.9 \\
4.6 \\
1.7 \\
6.0 \\
7.1 \\
7.3 \\
7.5\end{array}$ \\
\hline $\begin{array}{l}\text { IFA29 } \\
\text { Hollow } \\
\text { Pellets }\end{array}$ & 420 & $\begin{array}{l}3.05 \\
3.68 \\
4.40 \\
4.98 \\
5.43 \\
5.79\end{array}$ & $\begin{array}{l}1090 \\
1200 \\
1380 \\
1730 \\
1910 \\
2220\end{array}$ & $\begin{array}{l}2.92 \\
3.47 \\
6.57 \\
7.48 \\
7.57 \\
7.20\end{array}$ & $\begin{array}{l}2.9 \\
4.8 \\
5.1 \\
7.1 \\
7.6 \\
7.5\end{array}$ \\
\hline
\end{tabular}


TABLE 4. SPECIMEN TYPES

\begin{tabular}{|c|c|c|c|}
\hline Cluster & $\begin{array}{c}\text { Initial } \\
\text { Porosity, } \\
\%\end{array}$ & $\begin{array}{c}\text { Small Pore } \\
\text { Density }\end{array}$ & $\begin{array}{c}\text { Large Pore } \\
\text { Density }\end{array}$ \\
\hline$E 11 / 2$ & 3.65 & $1.55 \times 10^{9} / \mathrm{cm}^{3}$ & $5.73 \times 10^{7} / \mathrm{cm}^{3}$ \\
\hline $\mathrm{L} 09 / 2$ & 2.92 & $2.20 \times 10^{9} / \mathrm{cm}^{3}$ & $3.82 \times 10^{7} / \mathrm{cm}^{3}$ \\
\hline $\mathrm{Q} 03 / 2$ & 3.19 & $1.65 \times 10^{9} / \mathrm{cm}^{3}$ & $4.77 \times 10^{7} / \mathrm{cm}^{3}$ \\
\hline $\mathrm{L} 05 / 2$ & 3.65 & $1.55 \times 10^{9} / \mathrm{cm}^{3}$ & $5.73 \times 10^{7} / \mathrm{cm}^{3}$ \\
\hline IFA29 & 2.83 & $1.98 \times 10^{9} / \mathrm{cm}^{3}$ & $3.82 \times 10^{7} / \mathrm{cm}^{3}$ \\
\hline
\end{tabular}




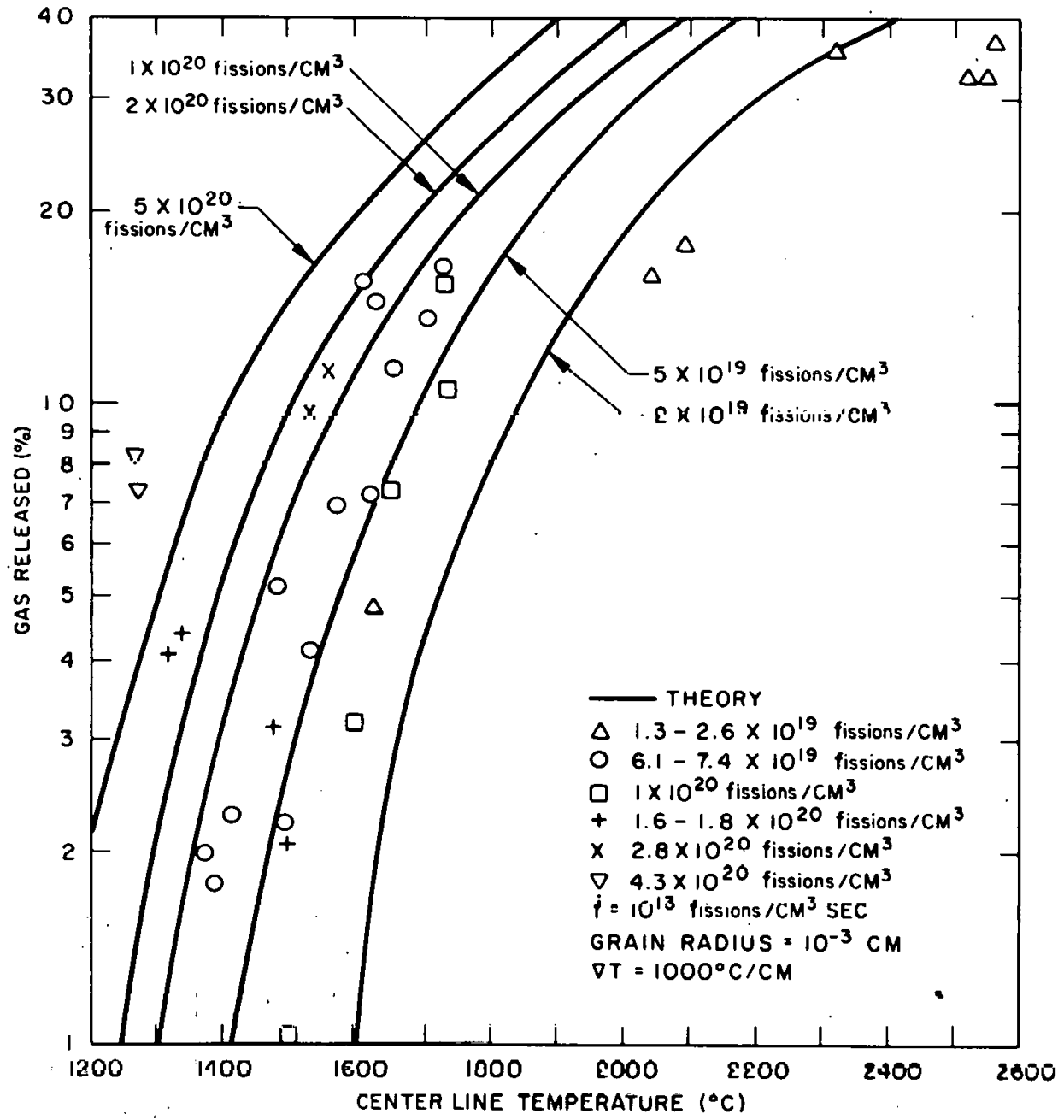

Figuro l. Gomparioono Botwoon Thoory and Data of Lewis (Reference 20) for the Release of $\mathrm{Gas}$ in $\mathrm{UO}_{2}$ 


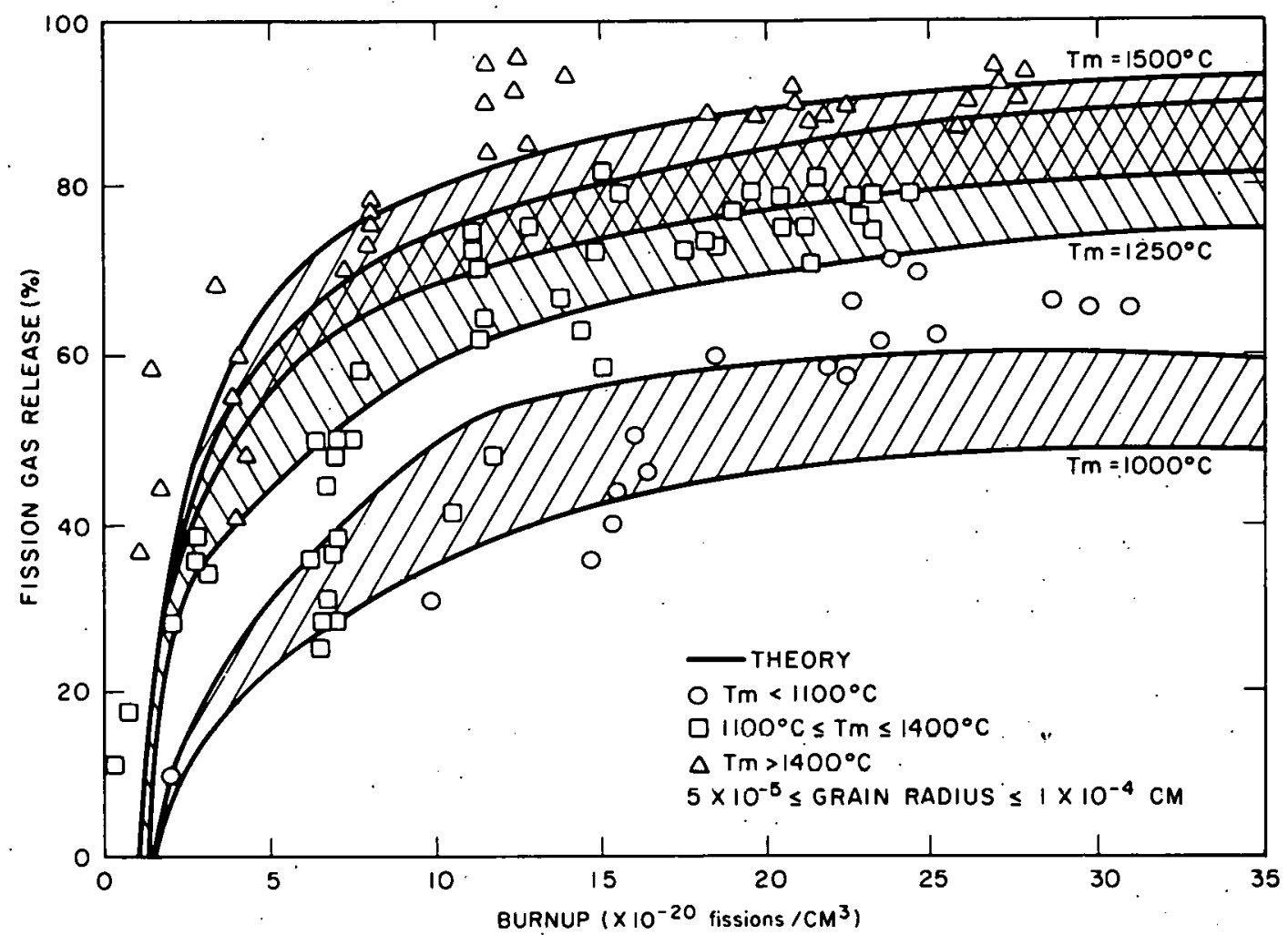

Figure 2. Comparisons Between Theory and Data of Zimmermann (Reference 21) for the Release of Gas in $\mathrm{UO}_{2}-20 \% \mathrm{PuO}_{2}$

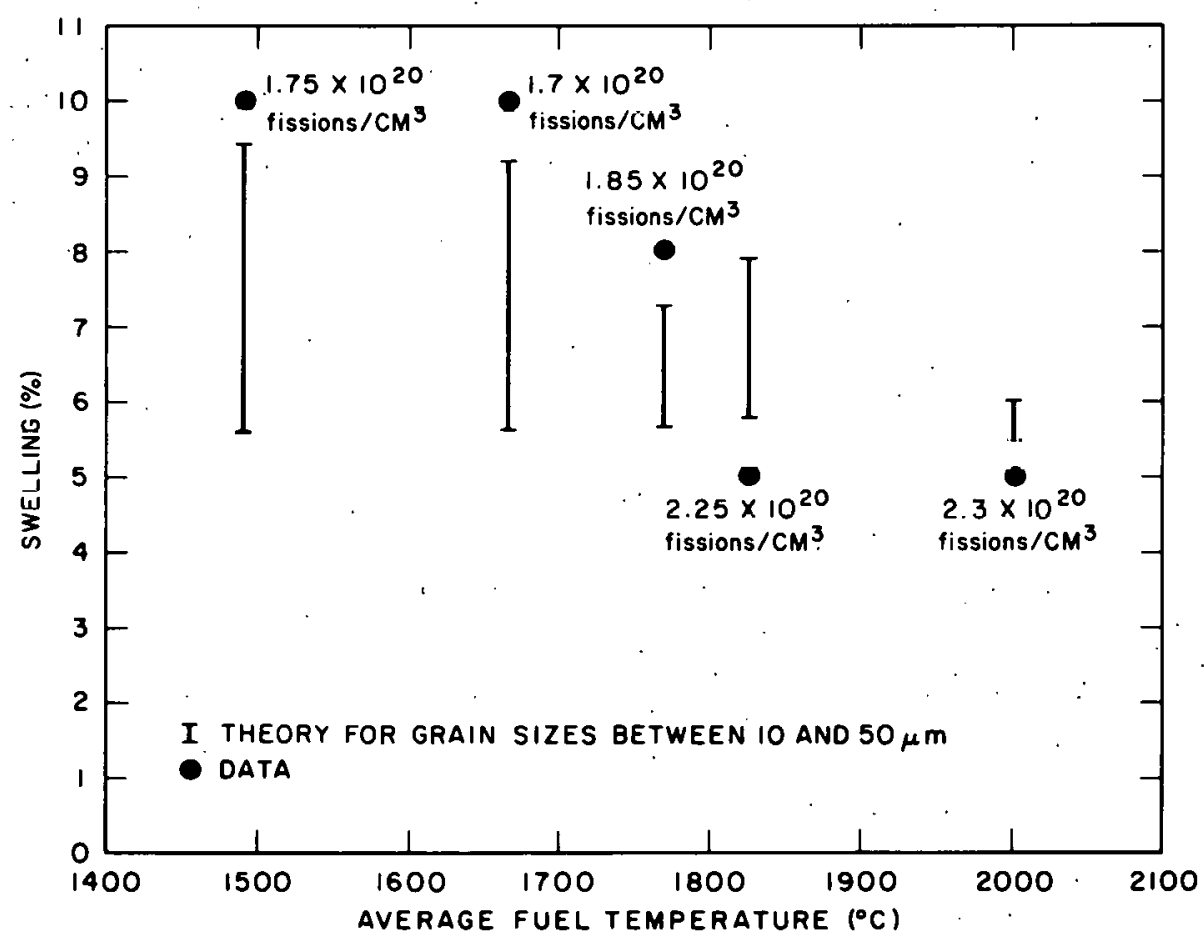

Figure 3. Comparison Between Theory and Data of Hilbert et al. (Reference 22) That Shows Swelling Versus Average Fuel Temperatures 


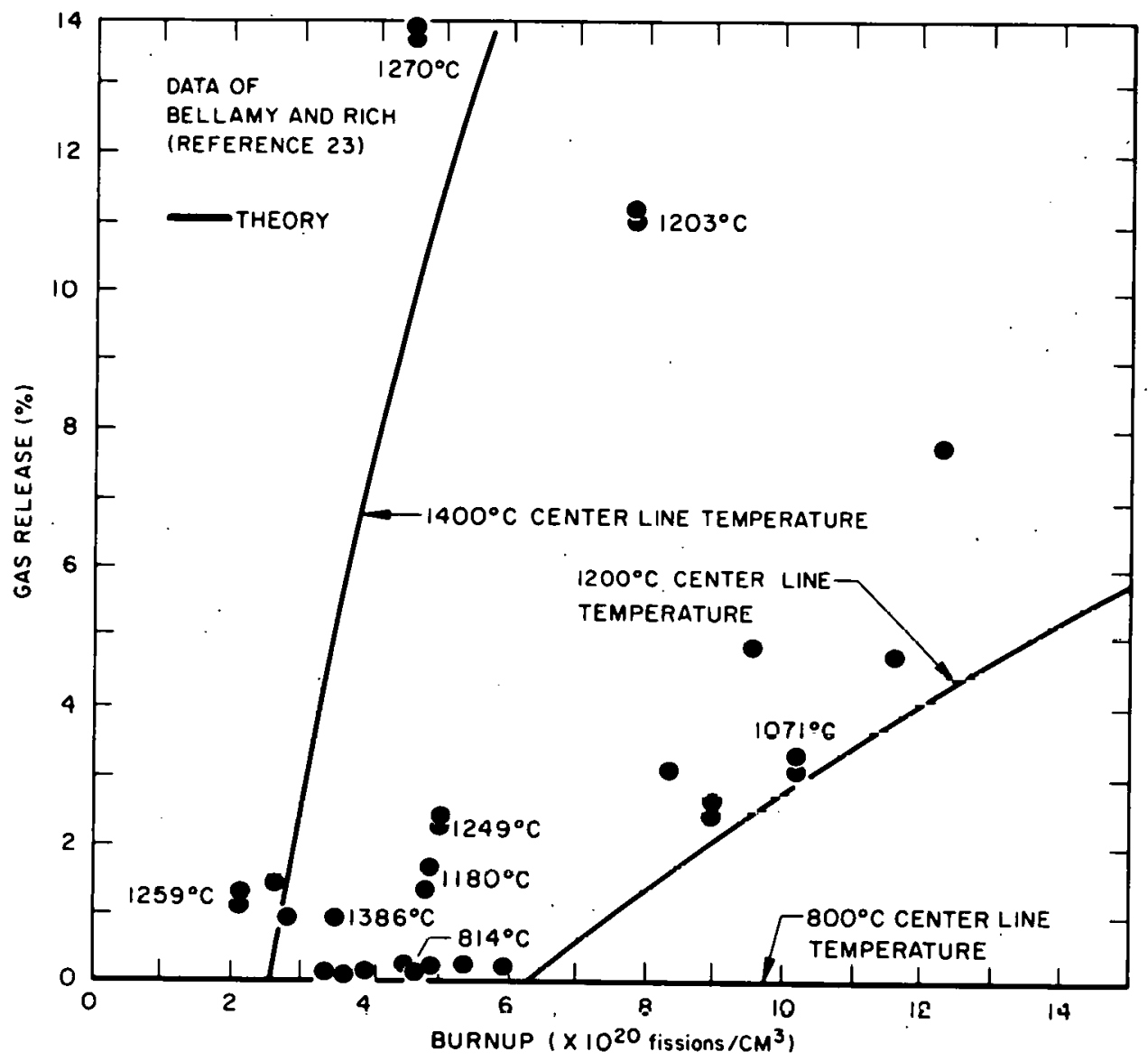

Figure 4. Gas Release Data of Bellamy and Rich (Reference 23) Versus Burnup

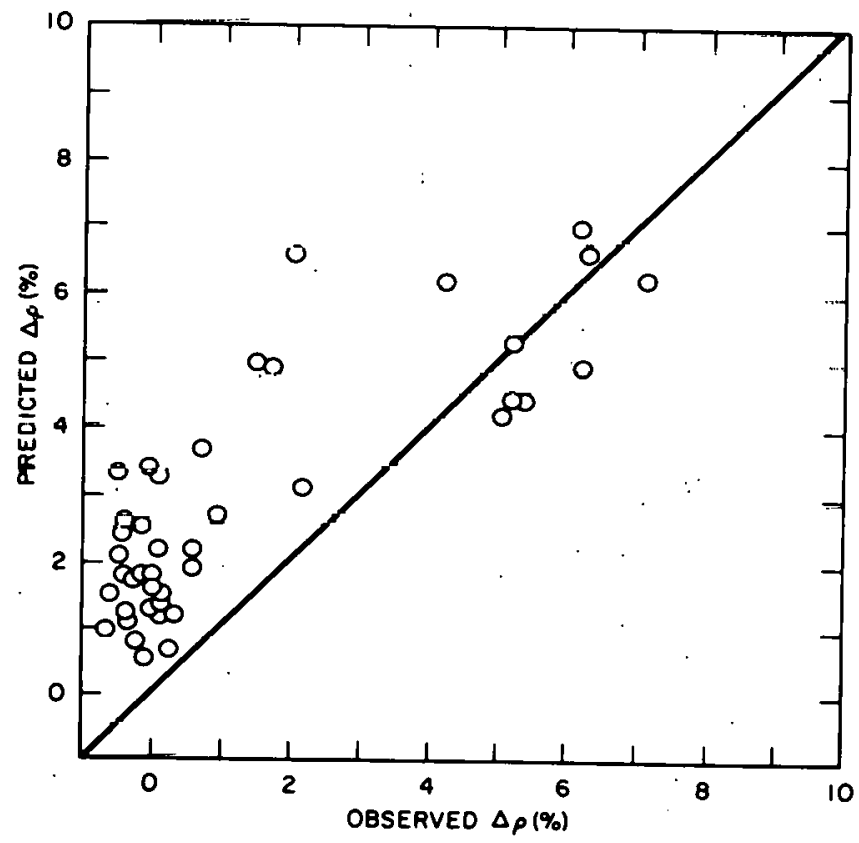

Figure 5. Comparison Between the Predicted and Observed Densification Data of Freshley et al. (Reference 24) 


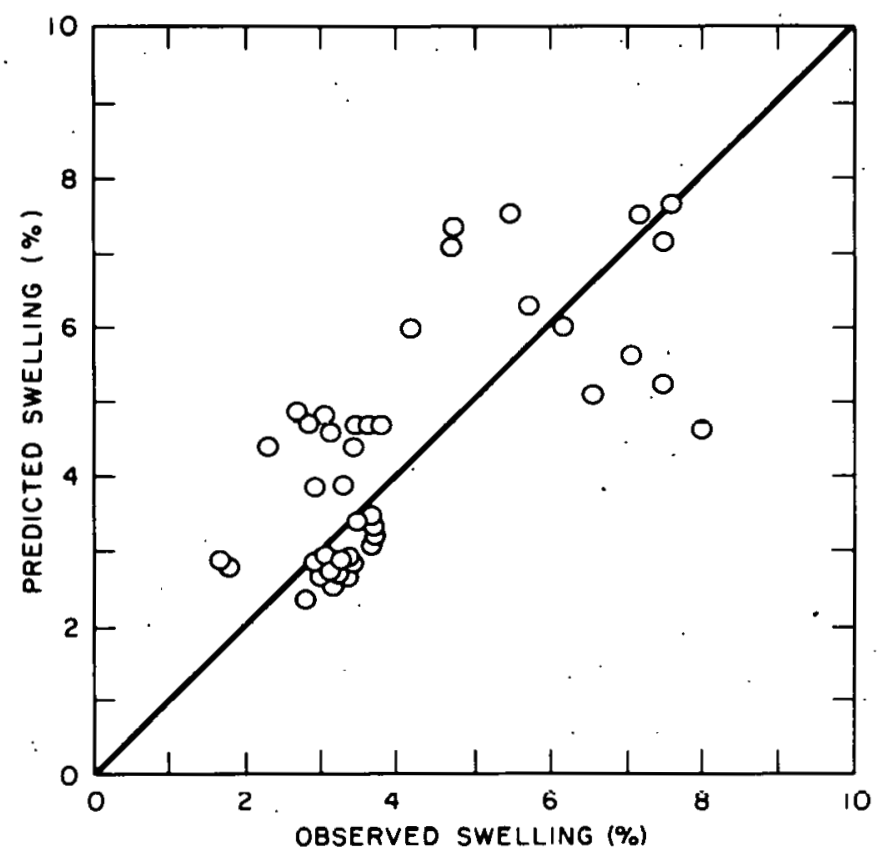

Figure 6. Comparison Between the Predicted and Observed Swelling Data of Banks (Reference 25) 